\title{
Surface Altered Zerolites as Permeable Barriers for In Situ Treatment of Contaminated Groundwater
}

\author{
Topical Report
}

November 1996

DISTAIBUTION OF THIS DOCUMENT IS UNLMITEO,

Work Performed Under Contract No.: DE-AR21-95MC32108

For

U.S. Department of Energy

Office of Environmental Management

Office of Technology Development

1000 Independence Avenue

Washington, DC 20585
U.S. Department of Energy

Office of Fossil Energy

Morgantown Energy Technology Center

P.O. Box 880

Morgantown, West Virginia 26507-0880
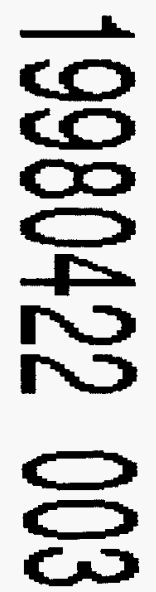

By

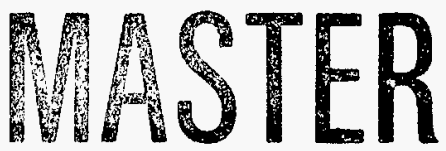

Department of Earth and Environmental Science

New Mexico Institute of Mining and Technology

Socorro, New Mexico 87801 


\section{Disclaimer}

This report was prepared as an account of work sponsored by an agency of the United States Government. Neither the United States Government nor any agency thereof, nor any of their employees, makes any warranty, express or implied, or assumes any legal liability or responsibility for the accuracy, completeness, or usefulness of any information, apparatus, product, or process disclosed, or represents that its use would not infringe privately owned rights. Reference herein to any specific commercial product, process, or service by trade name, trademark, manufacturer, or otherwise does not necessarily constitute or imply its endorsement, recommendation, or favoring by the United States Government or any agency thereof. The views and opinions of authors expressed herein do not necessarily state or reflect those of the United States Government or any agency thereof. 


\section{ACKNOWLEDGMENTS}

This work is being conducted for the DOE Office of Environmental Management at the Morgantown Energy Technology Center (METC). The Project Manager wishes to thank Mr. Karl-Heinz Frohne, the METC Contracting Officer's Representative, for his support and guidance. Support from Mr. Richard McQuisten (formerly of DOE) in developing the Statement of Work is also greatly appreciated.

The success of the work was made possible by the excellent research team at New Mexico Tech, comprised of Ioana Anghel, Zhaohui Li, Kirk Jones, Emily Keene, Edith Montoya, Leo Porta, Steve Roy, Jeri Sullivan, Jeanne Verploegh, Julia Whitworth, and Yiqiao Zou.

Collaborations with Dr. Douglas Hunter of the Savannah River Ecology Laboratory and Dr. J. William Carey of Los Alamos National Laboratory advanced our understanding of surfactantzeolite systems. 


\section{TABLE OF CONTENTS}

Page

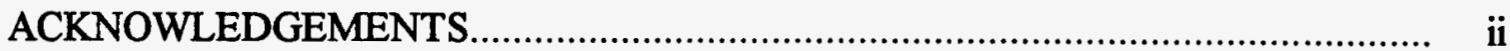

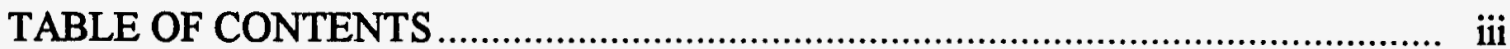

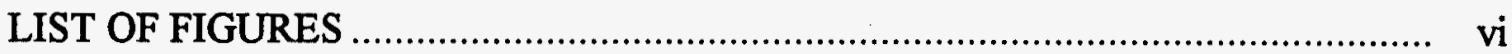

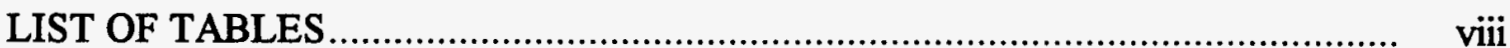

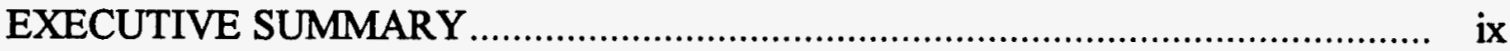

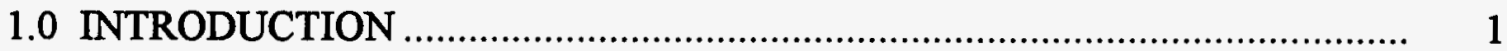

A. Statement of the Waste Management Problem ............................. 1

B. Physical and Chemical Features of Surfactant-Modified Zeolites ... 1

C. Intended use of the Technology ...................................................... 2

2.0 SCOPE OF WORK

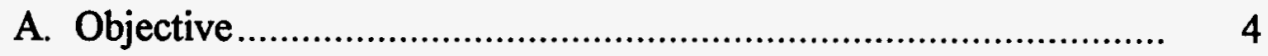

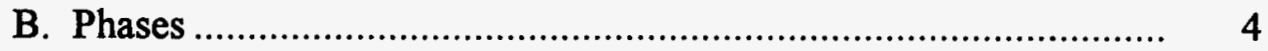

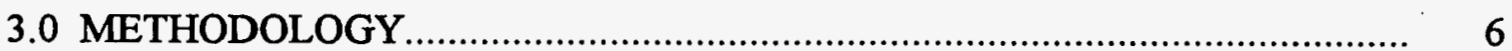

Task 1.1 Information required for the National Environmental Policy Act .... 6

Task 1.2 Develop laboratory production of SMZ ………............................ 6

A. Mineralogical characterization of zeolite ……………………....... 6

B. Determination of HDTMA sorption by zeolite ............................... 6

C. Preparation of HDTMA-modified zeolite ...................................... 6

Task 1.3 Determine effects of site-specific water chemistry on sorption of target compounds ................................................................... 7

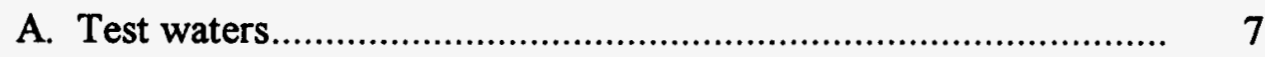

B. Chromate sorption ................................................................. 7

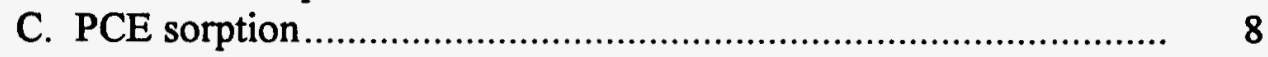


Task 1.4 Determine the long-term stability of SMZ ……..................................... 8

A. Chemical stability ..................................................................... 9

B. Biological stability .................................................................. 9

C. Advanced microscale characterization of SMZ surface stability .... 11

Task 1.5 Determine the possibility of regenerating SMZ .......................... 11

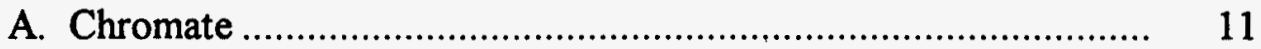

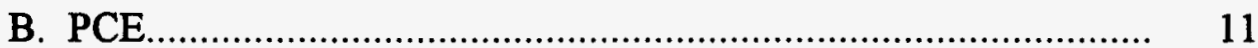

Task 1.6 Determine the ability to predict contaminant movement through beds of SMZ

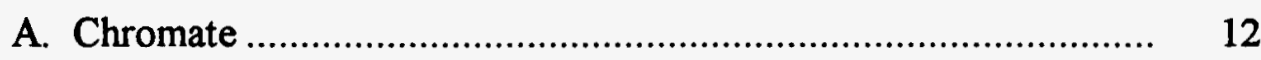

B. PCE

Task 1.7 Topical Report .................................................................... 14

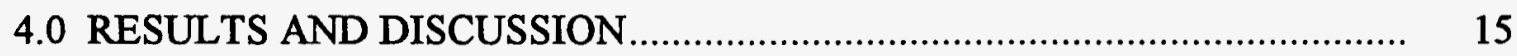

Task 1.1 Information required for the National Environmental Policy Act ... 15

Task 1.2 Develop laboratory production of SMZ ...................................... 15

A. Mineralogical characterization of zeolite ..................................... 15

B. Determination of HDTMA sorption by zeolite ............................. 15

C. Preparation of HDTMA-modified zeolite.................................... 17

Task 1.3 Determine effects of site-specific water chemistry on sorption of target compounds ............................................................... 18

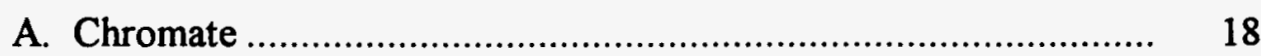

B. PCE

Task 1.4 Determine the long-term stability of SMZ .................................... 24

A. Chemical stability ................................................................... 24

B. Biological stability ........................................................................ 25

C. Advanced microscale characterization of SMZ surface stability ... 26

Task 1.5 Determine the possibility of regenerating SMZ …...................... 28

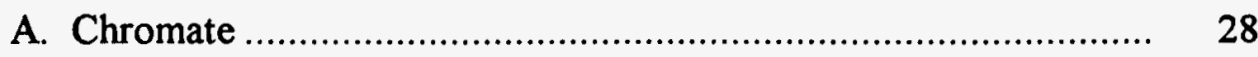

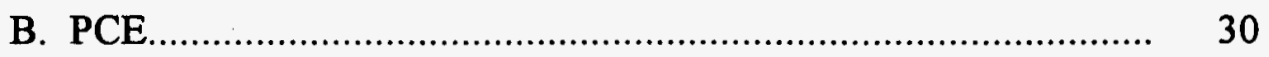


Task 1.6 Determine the ability to predict contaminant movement through beds of SMZ ................................................................ $3 \mathbf{1}$

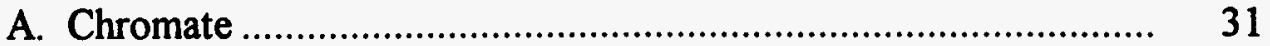

B. PCE....................................................................... 33

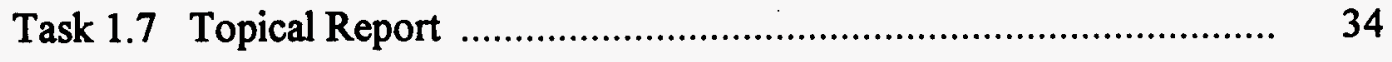

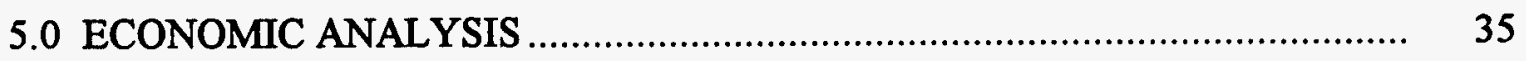

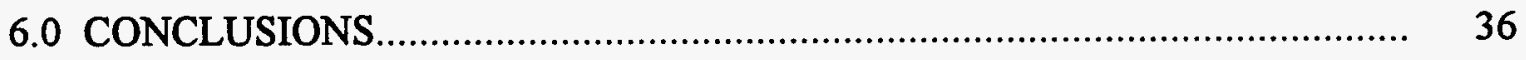

A. Results of Phase I ..................................................... 36

B. Outlook for Phase II ................................................... 36

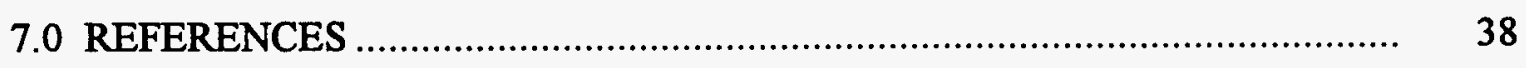

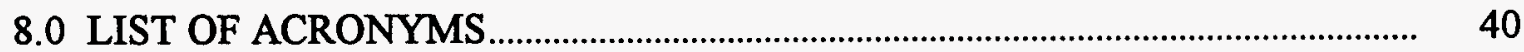




\section{LIST OF FIGURES}

Figure 1-1. Schematic diagram of SMZ in a permeable barrier installation

Figure 2-1. Phase I personnel management, with primary responsibility for Phase I tasks indicated.

Figure 3-1. Schematic diagram of microcosm used in biological stability determinations

Figure 3-2. Schematic diagram of laboratory column setup for chromate transport experiments

Figure 3-3. Schematic diagram of laboratory column setup for PCE transport experiments.

Figure 4-1. Sorption isotherms for HDTMA-Br, HDTMA-C1, and $\mathrm{HDTMA}^{-\mathrm{HSO}_{4}}$ on zeolite

Figure 4-2. HDTMA-Br sorption by zeolite as a function of mixing time.

HDTMA-Br added at a rate of $75 \%$ of the sorption maximum.

Figure 4-3. Particle size distribution of SMZ (treated) versus raw (untreated) zeolite 18

Figure 4-4. Sorption isotherm for chromate dissolved in deionized water. The solid line is a Langmuir isotherm fit to the data

Figure 4-5. Sorption isotherms for chromate dissolved in waters from Elizabeth City, NC, and Hanford, WA

Figure 4-6. Chromate sorption by SMZ prepared using HDTMA-Br, HDTMA-Cl, or HDTMA-HSO

Figure 4-7. Chromate sorption by SMZ as a function of surface coverage for HDTMA-Br. Numbers on lines indicate the amount of HDTMA on the zeolite surface 21

Figure 4-8. Chromate sorption by SMZ as a function of surface coverage for HDTMA-Cl. Numbers on lines indicate the amount of HDTMA on the zeolite surface 
Figure 4-9. Sorption isotherms for PCE dissolved in deionized water, and in waters from Elizabeth City, NC, and Oak Ridge, TN.

Figure 4-10. PCE sorption by SMZ prepared using HDTMA-Br or HDTMA-Cl ....... 23

Figure 4-11. PCE sorption by SMZ as a function of HDTMA surface coverage for HDTMA-Br and HDTMA-Cl. $\mathrm{K}_{\mathrm{D}}$ is the slope of the linear sorption isotherm at each loading rate

Figure 4-12. Percentage of original HDTMA remaining on SMZ after washing with 100 pore volumes of various reagents.

Figure 4-13. Percentage of original HDTMA remaining on SMZ after incubation with activated sludge under aerobic (14 weeks) and anaerobic (8 weeks) conditions

Figure 4-14. Derivative weight loss curves for thermogravimetric analysis of SMZ at different HDTMA surface coverages (\% of ECEC, the external cation exchange capacity)

Figure 4-15. Enthalpy changes associated with sorption of HDTMA and tetraethyl ammonium (TEA) on raw zeolite

Figure 4-16. Percentage of sorbed chromate extracted by various reagents from chromate-saturated SMZ.

Figure 4-17. Sorption of chromate on regenerated $\left(\mathrm{Na}_{2} \mathrm{CO}_{3} / \mathrm{NaOH}\right)$ and virgin $\mathrm{SMZ}$.. 29

Figure 4-18. Sorption of PCE on regenerated (air-stripped) and virgin SMZ ............. 30

Figure 4-19. Sorption of PCE on regenerated $\left(\mathrm{Na}_{2} \mathrm{CO}_{3} / \mathrm{NaOH}\right)$ and virgin $\mathrm{SMZ} \ldots \ldots . . .31$

Figure 4-20. Tritium breakthrough curves for columns packed with untreated zeolite and with SMZ (chromate experiment)

Figure 4-21. Chromate breakthrough curves for columns packed with untreated zeolite and with SMZ.

Figure 4-22 Tritium breakthrough curves (raw count values) for columns packed with untreated zeolite and with SMZ (PCE experiment)

Figure 4-23. PCE breakthrough curves (raw count values) for columns packed with untreated zeolite and with SMZ . 


\section{LIST OF TABLES}

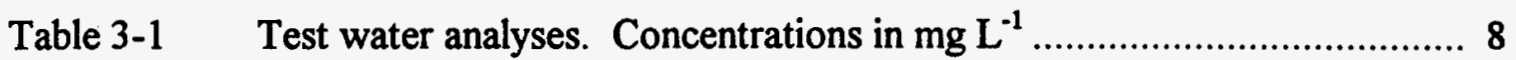

Table 3-2. Solutions used to evaluate chemical stability of SMZ .............................. 9

Table 3-3. Experimental conditions used to evaluate biological stability of SMZ..... 10

Table 3-4. Extraction reagents tested for regenerating chromate-saturated SMZ .... 12

Table 4-1. Mineralogical analysis of St. Cloud zeolite......................................... 15

Table 4-2. Elemental analysis of St. Cloud zeolite before and after surfactant

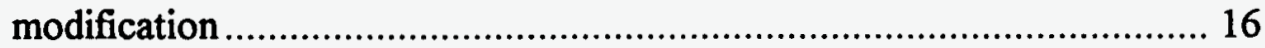

Table 5-1. Commercial sources, properties, and costs of HDTMA ...................... 35 


\section{EXECUTIVE SUMMARY}

We characterized surfactant-modified zeolite (SMZ) for its ability to sorb organic and inorganic contaminants from water. Our ultimate objective is to use $\mathrm{SMZ}$ as a permeable barrier to prevent migration of contaminants in groundwater. This report summarizes results under Phase I of a three-Phase project leading to a full-scale field demonstration of SMZ permeablebarrier technology.

We prepared a large batch $(30 \mathrm{~kg})$ of SMZ using simple mixing equipment. We determined that the SMZ sorbed up to $210 \mathrm{mmol} \mathrm{kg}^{-1}$ ( $6 \%$ by weight) of the surfactant hexadecyltrimethylammonium bromide (HDTMA-Br), and lesser amounts of HDTMA-Cl and HDTMA-HSO ${ }_{4}$. The SMZ was effective in sorbing the contaminants chromate and perchloroethylene (PCE) from aqueous solution. Up to $14 \mathrm{mmol} \mathrm{kg}^{-1}$ (about $1600 \mathrm{mg} \mathrm{kg}^{-1}$ ) of chromate could be sorbed onto SMZ from distilled water. Sorption from chromate-contaminated waters from Elizabeth City, NC, and Hanford, WA, was somewhat lower, but SMZ still removed more than $90 \%$ of dissolved chromate. Similarly, SMZ removed more than $85 \%$ of PCE from distilled water and waters from Elizabeth City and Oak Ridge, TN.

The SMZ was resistant to chemical and biological deterioration. More than $90 \%$ of the original surfactant treatment remained on the SMZ after washing with 100 pore volumes of acidic (pH 3), basic (pH 9), reducing $\left(0.1 M \mathrm{Na}_{2} \mathrm{~S}_{2} \mathrm{O}_{4}\right)$, or high ionic strength $\left(1.0 M \mathrm{CaCl}_{2}\right)$ solutions. Low ionic strength solutions (deionized water and $5 \% \mathrm{H}_{2} \mathrm{O}_{2}$ ) removed about $20 \%$ of the surfactant treatment after 100 pore volumes. Only $1.0 \mathrm{M} \mathrm{CsCl}_{2}$ was able to remove more than 20 $\%$ of the surfactant after 100 pore volumes.

More than $95 \%$ of the original surfactant treatment remained intact on the SMZ after 2-4 months incubation under aerobic and anaerobic conditions. In addition, SMZ did not inhibit microbial activity.

We were able to regenerate SMZ saturated with chromate or PCE. Chromate-saturated SMZ was regenerated by washing with $0.28 \mathrm{MNa}_{2} \mathrm{CO}_{3} / 0.5 \mathrm{MNaOH}$. Perchloroethylenesaturated SMZ was regenerated by air stripping. Both of these regeneration methods could be used for in situ regeneration. The regenerated material fully regained its original sorption capacity for chromate and PCE.

Laboratory column transport experiments were designed based on the sorption and stability behavior of the SMZ. We passed a nonreactive tracer and solutions of chromate and PCE in simulated groundwater through packed beds of SMZ. These transport experiments, which will test our ability to predict the migration of contaminants through SMZ, are currently in progress.

We estimate the cost of SMZ in large quantities to be about $\$ 500$ ton $^{-1}\left(\$ 15 \mathrm{ft}^{-3}\right)$. This makes it very cost-competitive with other large-volume sorbents/reactants such as activated carbon, ion-exchange resins, and iron filings.

This Phase I work proves that SMZ is a stable and effective sorbent for removing metallic and organic contaminants from water. It justifies continuation of the work into Phase II, pilotscale testing of permeable barrier technology. 


\subsection{INTRODUCTION}

\section{A. Statement of the Waste Management Problem}

Environmental cleanup of DOE and other government and military facilities has become a high priority. Disposal at many of these sites (such as Los Alamos, Hanford, Rocky Flats, Oak Ridge, and others) has resulted in low-level wastes that are distributed in shallow, broad areas. These wastes are complex mixtures that often include chromate and chlorinated and non-chlorinated organic compounds. Many sites have contamination that is spreading and needs containment. In fact, containment may be the best short- and long-term solution for many DOE, DOD, Superfund, industrial, landfill, and mining sites. Site closure and postclosure monitoring are regulatory requirements under Superfund (CERCLA and/or SARA), RCRA, and DOE Order 5820.2A. Monitoring periods extend from 30 to 100 years for hazardous and radioactive contaminants, respectively, indicating the need for long-term, lowmaintenance, and low-cost solutions. The development of sorbent/reactive materials for permeable barriers will provide a better tool for dealing with these complex contamination problems.

Contaminants at the above-mentioned sites are often mixed wastes that may be mobile in groundwater, posing immediate risks to on- and off-site receptors. A particularly difficult problem is the presence of residual contamination by water-immiscible organics that cannot be removed by traditional pump-and-treat methods (Fetter, 1993). Low concentrations of organics are continuously released into the groundwater by slow dissolution of the residual liquid. Metals such as arsenic, hexavalent chromium, and selenium are also often present at these sites. These metal species are negatively charged (anionic) and are therefore mobile in most aquifers. Conventional treatment processes are typically ineffective for the removal of these anionic compounds. The use of surfactant-modified zeolite (SMZ) in permeable barriers appears to offer unique advantages over conventional processes in removal of both anionic metals as well as dissolved organic compounds from solution.

\section{B. Physical and Chemical Features of Surfactant-Modified Zeolites}

Zeolites are hydrated aluminosilicate minerals characterized by cage-like structures, high internal and external surface areas, and high cation exchange capacities. Both natural and synthetic zeolites find use in industry as sorbents, soil amendments, ion exchangers, and molecular sieves. Clinoptilolite is the most abundant naturally occurring zeolite. It has a twodimensional 8-ring and 10-ring channel structure with the largest cavity dimension measuring 4.4 by 7.2 (Newsom, 1986). The unit-cell formula is $\left(\mathrm{Ca}, \mathrm{Na}_{2}, \mathrm{~K}_{2}\right)_{3}\left[\mathrm{Al}_{6} \mathrm{Si}_{30} \mathrm{O}_{72}\right] 24 \mathrm{H}_{2} \mathrm{O}$. The low cost of natural zeolites $(\$ 60-\$ 100 /$ ton) makes their use attractive in water treatment applications.

Zeolite chemistry resembles that of smectite clays. In contrast to clays, however, natural zeolites can occur as millimeter- or greater-sized particles and are free of shrink-swell behavior. As a result, zeolites exhibit superior hydraulic characteristics and are suitable for use in filtration systems (Breck, 1974) and as permeable barriers to dissolved chemical migration. Internal and external surface areas up to $800 \mathrm{~m}^{2} / \mathrm{g}$ have been measured. Total cation exchange capacities in natural zeolites vary from 25 to $300 \mathrm{meq} / 100 \mathrm{~g}$ (Ming and Mumpton, 1989; Sheppard and Gude, 1982). External cation exchange capacities have been 
determined for a few natural zeolites and typically range from 30 to 50 percent of the total cation exchange capacity (Flynn, 1994).

Due to their large specific surface areas and high cation exchange capacities, natural zeolites have a high affinity for cationic heavy metals such as $\mathrm{Pb}^{2+}$ and $\mathrm{Cd}^{2+}$. Zeolites have been used commercially to remove $\mathrm{Pb}^{2+}$ and ammonia $\left(\mathrm{NH}_{4}{ }^{+}\right.$) from waste waters (Groffman et al., 1992; Mumpton and Fishman, 1977). However, natural zeolites have little affinity for inorganic anions such as chromate $\left(\mathrm{CrO}_{4}{ }^{2-}\right)$ or for dissolved organics.

Treatment of natural zeolites with cationic surfactants dramatically alters their surface chemistry. The large organic cations exchange essentially irreversibly with native cations such as $\mathrm{Na}^{+}, \mathrm{K}^{+}$, or $\mathrm{Ca}^{2+}$. Surfactant modification of zeolites enables them to sorb neutral molecules such as benzene and chlorinated hydrocarbons including tetrachloroethene and 1,1,1-trichloroethane, while retaining their ability to sorb heavy metal cations (Bowman et al., 1995; Flynn, 1994; Neel, 1991; Huddleston, 1990). It has also been shown that strongly hydrolyzed, anionic metals such as arsenic, chromium, and selenium are selectively removed by SMZ (Haggerty and Bowman, 1994). The removal of these toxic anions is also quite dramatic. While a variety of surfactants can be used for alteration of zeolite surface chemistry (Neel, 1991; Huddleston, 1990), hexadecyltrimethylammonium (HDTMA) is preferred due to its ready availability and low cost.

The work described above shows that SMZ can simultaneously remove organics, inorganic cations, and inorganic anions from contaminated water.

\section{Intended Use of the Technology}

Because of the broad sorptive capabilities of SMZ, its superior hydraulic characteristics, its low unit cost, and the historical use of zeolites in water treatment facilities, this material is very promising as a sorbent for in situ treatment of contaminated groundwater. Figure 1-1 shows a schematic diagram of SMZ used in a permeable barrier installation.

Barrier materials which retain organic compounds, radionuclides, and other hazardous contaminants while allowing the passage of groundwater are needed to prevent plume migration from near-surface waste sites. Such barriers will allow concentration of contaminants in a narrow zone, increasing the efficiency and lowering the costs of other in situ treatment methods such as enhanced biodegradation or air stripping. This project is aimed at completely characterizing the sorptive properties of SMZ and demonstrating its use as a permeable barrier in a full-scale field installation. 


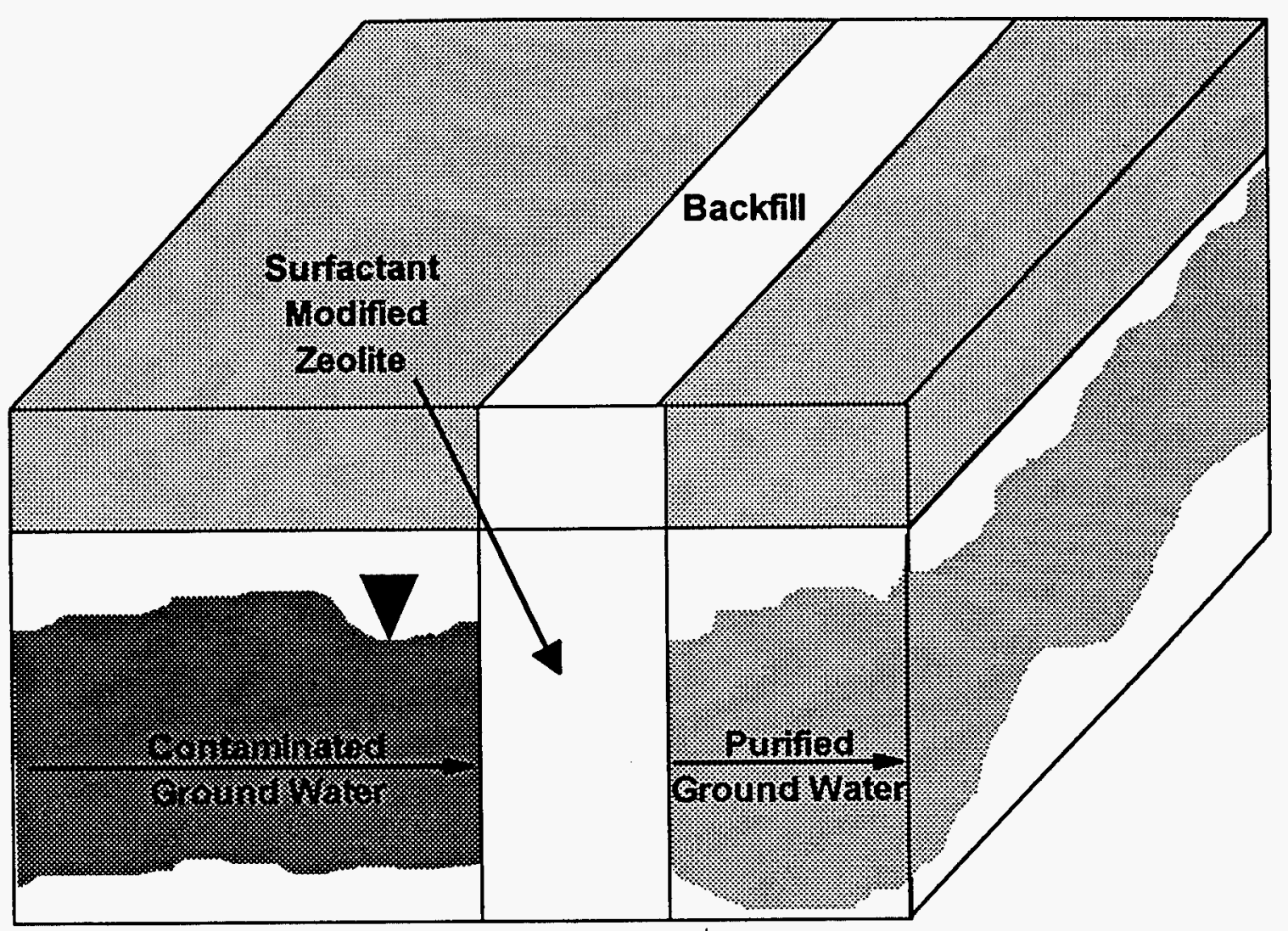

Figure 1- 1 Schematic diagram of SMZ in a permeable barrier installation. 


\subsection{SCOPE OF WORK}

\section{A. Objective}

The overall objective of this effort is to develop and test a zeolite-based permeable barrier system(s) for containing and remediating contaminated groundwater. The projected product is an engineered and tested permeable barrier system that can be adopted by the commercial sector.

\section{B. Phases}

The project consists of three phases: a base phase (Phase I), which this report summarizes, and two optional phases (Phases II and III). In Phase I we characterized the stability of SMZ as well as its properties with respect to sorption and transport of target groundwater contaminants. In optional Phase II, we will perform pilot-scale tests of a permeable barrier system using engineering criteria relevant to field-scale problems and develop a standard protocol for testing barrier technology. In optional Phase III, we shall test the Phase I and II barrier technology at a field demonstration site to determine its efficacy and commercial value.

The specified Tasks of the three phases are listed below.

\section{Phase I: $\quad$ Laboratory Bench Testing and Analysis (Duration: 15 months)}

Task 1.1 Information required for the National Environmental Policy Act

Task 1.2 Develop laboratory production of SMZ

Task 1.3 Determine effects of site-specific water chemistry on sorption of target compounds

Task 1.4 Determine the long-term stability of SMZ

Task 1.5 Determine the possibility of regenerating SMZ

Task 1.6 Determine the ability to predict contaminant movement through beds of SMZ

Task 1.7 Topical Report

\section{Phase II: Pilot-Scale Testing of Barrier Technology (Duration: 15 months)}

Task 2.1 Information required for the National Environmental Policy Act

Task 2.2 Identify a suitable test-bed facility

Task 2.3 Develop experimental, quality control, and analysis protocol for pilot-scale engineering testing

Task 2.4 Develop engineering criteria for barrier technology installation

Task 2.5 Pilot-Scale Testing and Analysis

Task 2.6 Topical Report

\section{Phase III: Field Demonstration (Duration: 15 months)}

Task 3.1 Information required for the National Environmental Policy Act

Task 3.2 Identify field demonstration site(s) and develop action plan for demonstrating barrier technology

Task 3.3 Develop experimental. quality control, and analysis protocol for the field site demonstration

Task 3.4 Conduct field demonstration experiments and engineering analysis 
Task 3.5 Compare Phase I, II, and III results

Task $3.6 \quad$ Final Report

The personnel management plan for Phase I is presented in Figure 2.1, with primary responsibility for Phase I tasks indicated.

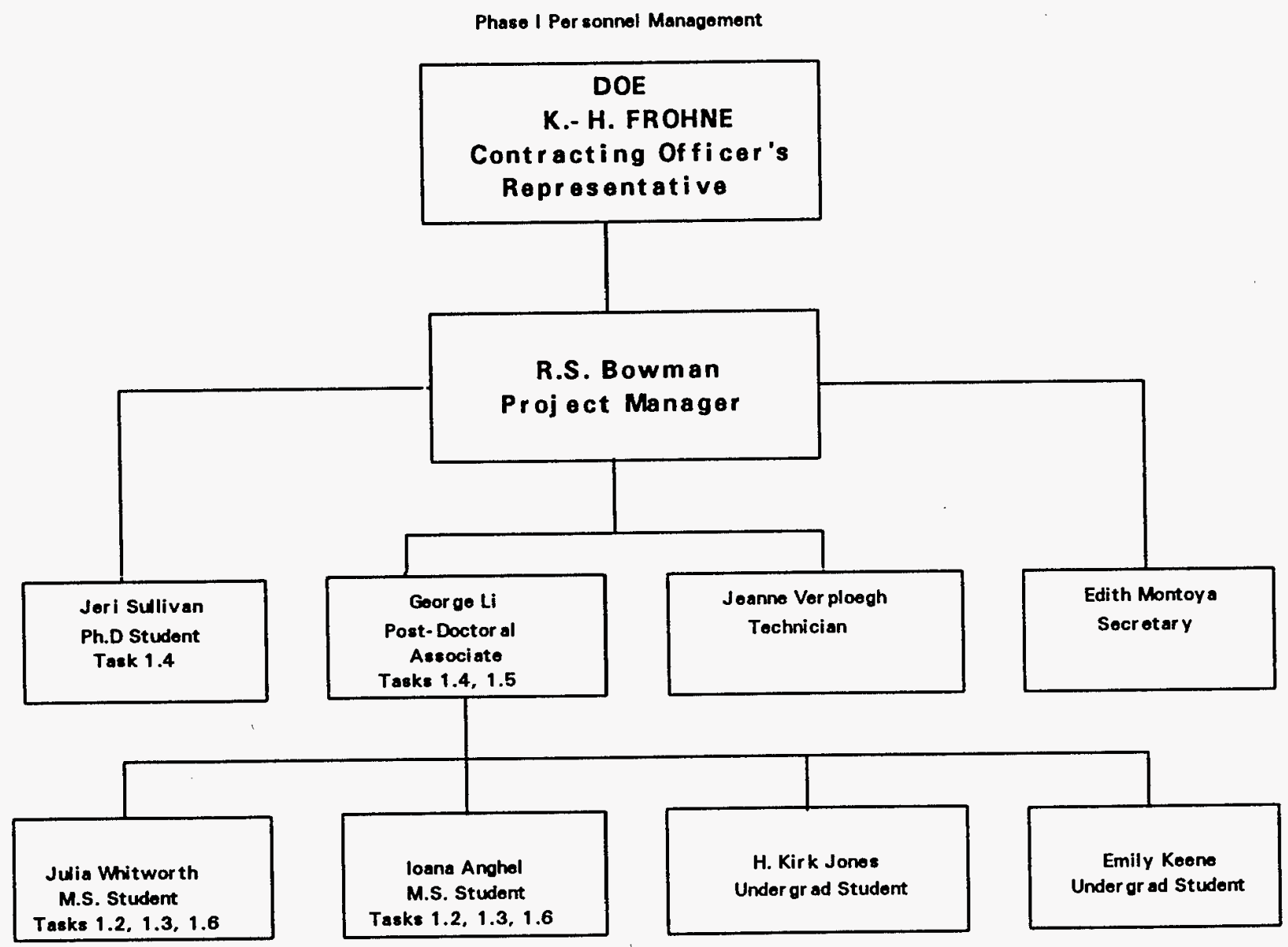

Figure 2- 1 Phase I personnel management, with primary responsibility for Phase I tasks indicated. 


\subsection{METHODOLOGY}

Task 1.1 Information required for the National Environmental Policy Act

The appropriate documentation was submitted prior to initiation of the Phase I laboratory experiments.

\section{Task 1.2 Develop laboratory production of SMZ}

The major objective under this task was to develop methods to produce large quantities (kilograms to tons) of SMZ, which will be required for work under Phase II and Phase III. Onehalf ton of sized zeolite (14-40 mesh, 1.4- 0.4 mm) was obtained from the producer (St. Cloud Mining Co., Truth or Consequences, NM). This material was used for all Phase I experimentation.

\section{A. Mineralogical characterization of zeolite}

The mineralogical and elemental composition of the zeolite was determined by X-ray diffraction and X-ray fluorescence spectroscopy, respectively. The elemental composition was determined both before and after treatment with HDTMA.

\section{B. Determination of HDTMA sorption by zeolite}

Previous work (Haggerty and Bowman, 1994; Bowman et al., 1995) had shown that HDTMA was sorbed by zeolite quantitatively up to a sorption maximum, or plateau, beyond which little additional HDTMA was retained. The first step, thus, was to characterize the HDTMA sorption maximum for this batch of zeolite. We prepared a sorption isotherm by combining $5 \mathrm{~g}$ of zeolite with $20 \mathrm{~mL}$ of HDTMA-Br, HDTMA-Cl, or $\mathrm{HDTMA}^{-\mathrm{HSO}_{4}}$ solution in a polyallomer centrifuge tube. Duplicate samples and appropriate blanks were prepared for each initial condition. For these experiments we utilized ${ }^{14} \mathrm{C}$-HDTMA to provide accurate quantitation of HDTMA sorption. Each zeolite-HDTMA mixture was shaken for $24 \mathrm{~h}$ at $25 \mathrm{C}$ (a period shown in preliminary experiments to be sufficient to attain equilibrium), centrifuged, and $1 \mathrm{~mL}$ of the clear supernatant solution analyzed via liquid scintillation counting. The amount of HDTMA sorbed was determined from the difference between initial and final solution concentrations.

\section{Preparation of HDTMA-modified zeolite}

We prepared $30 \mathrm{~kg}$ of HDTMA-modified zeolite. This was a quantity sufficient for all Phase I experimentation, and intermediate between laboratory-scale and field-scale quantities. We thus gained experience relevant to producing the large quantities of modified zeolite required for Phases II and III. We targeted an HDTMA treatment level of $90 \%$ of the sorption maximum (200 mmol HDTMA $/ \mathrm{kg}$ zeolite). We combined $120 \mathrm{~L}$ (32.0 gal) of $0.056 \mathrm{MHDTMA}-\mathrm{Br}$ solution with $30 \mathrm{~kg}(66 \mathrm{lb})$ of zeolite in a $273 \mathrm{~L} \mathrm{(73} \mathrm{gal)} \mathrm{metal} \mathrm{drum.} \mathrm{The} \mathrm{slurry} \mathrm{was} \mathrm{mixed} \mathrm{with}$ a flat-blade stirrer at low speed for $72 \mathrm{~h}$. The concentration of HDTMA remaining in solution was determined by HPLC, which verified that $>95 \%$ of the added HDTMA had been sorbed by the zeolite. The supernatant solution was drained, the zeolite was rinsed once with tap water under gentle stirring, the rinse water was drained, and the wet HDTMA-modified zeolite was 
spread on plastic sheeting to air-dry. The dry zeolite was homogenized by passing it through a soil splitter and then packaged in $5-\mathrm{kg}$ quantities in plastic bags.

This $30-\mathrm{kg}$ batch prepared with HDTMA-Br was used for the majority of the testing in Tasks 1.3, 1.4, 1.5, and 1.6. Some smaller batches of SMZ were prepared using HDTMA-Cl and HDTMA-HSO ${ }_{4}$ in order to test the effects of different counterions on HDTMA sorption to zeolite and on the contaminant sorption properties of the resultant SMZ.

Task 1.3 Determine effects of site-specific water chemistry on sorption of target compounds

The major objective under this task was to determine how other components in actual contaminated groundwaters would affect sorption of target contaminants by SMZ. We chose chromate as an inorganic contaminant of environmental concern that is representative of mobile oxyanions such as arsenate, selenate, molybdate, and pertechnetate. Other work (Haggerty and Bowman, 1995; unpublished data) has shown that all of these species are sorbed by SMZ. We chose PCE as an organic contaminant of environmental concern which was representative of nonpolar organics such as chlorinated solvents and fuel components. We have shown (Bowman et al., 1995) that the SMZ sorption of a wide range of nonpolar organics is highly correlated to the organic's octanol/water partition coefficient $\left(\mathrm{K}_{\mathrm{ow}}\right)$. Thus, water-specific effects determined for PCE sorption may be extrapolated to the sorption of other organics (including other chlorinated organics and petroleum components) by SMZ.

\section{A. Test waters}

Four different waters were used as background solutions in tests of chromate and PCE sorption. The first was deionized (Type I) water with a $\mathrm{pH}$ of 7 . Sorption from deionized water served as the standard to which sorption from other waters was compared. The other waters were synthesized based on analyses from actual groundwater contamination sites. The second water was from a contaminated Coast Guard facility in Elizabeth City, NC, which has a commingled chromate and PCE plume. The third water was from a chromate-contaminated spring $(100-\mathrm{H})$ which discharges into the Columbia River at DOE's Hanford facility in Washington. The fourth water was from PCE-contaminated groundwater near the Y-12 plant at DOE's Oak Ridge National Laboratory. The analysis of major cations and anions for each of these waters is presented in Table 3-1.

\section{B. Chromate sorption}

Chromate sorption was determined in matrices of deionized water and test waters from Elizabeth City and Hanford (Table 3-1). Sorption isotherms were prepared using initial chromate concentrations of 12.5 to $800 \mathrm{mg} \mathrm{L}^{-1}$. Duplicate samples and appropriate blanks were prepared for each initial condition. For each initial condition, $20 \mathrm{~mL}$ of the appropriate chromate solution was added to $5 \mathrm{~g}$ of SMZ in a 50-mL polyallomer centrifuge tube. The tubes were shaken for 24 $\mathrm{h}$ at $25^{\circ} \mathrm{C}$ (preliminary experiments showed equilibrium was attained within $1 \mathrm{~h}$ ), centrifuged, and the supernatants analyzed for chromate via HPLC. Chromate sorption was determined from the difference between initial and final solution concentrations, with appropriate corrections based on blanks. 
Table 3- 1 Test water analyses. Concentrations in $m g L^{-1}$.

Water Source

\begin{tabular}{|c|c|c|c|c|}
\hline Species & $\begin{array}{l}\text { Deionized } \\
\text { Water }\end{array}$ & $\begin{array}{l}\text { Elizabeth City, } \\
\text { North Carolina }\end{array}$ & $\begin{array}{l}\text { Hanford, } \\
\text { Washington }\end{array}$ & $\begin{array}{l}\text { Oak Ridge } \\
\text { National Lab }\end{array}$ \\
\hline $\mathrm{Al}^{3+}$ & 0.0 & 0.07 & 0.0 & 3.1 \\
\hline $\mathrm{Ca}^{2+}$ & 0.0 & 25.7 & 33.46 & 56.5 \\
\hline $\mathrm{Fe}^{2+}$ & 0.0 & 0.21 & 0.0 & 2.45 \\
\hline $\mathrm{Mg}^{2+}$ & 0.0 & 16.0 & 5.83 & 6.57 \\
\hline $\mathrm{K}^{+}$ & 0.0 & 0.0 & 1.56 & 5.30 \\
\hline $\mathrm{Na}^{+}$ & 0.0 & 81 & 9.89 & 14.5 \\
\hline $\mathrm{Cl}^{-}$ & 0.0 & 103 & 3.19 & 29.5 \\
\hline$\left(\mathrm{HCO}_{3}\right)^{-}$ & 0.0 & 57.0 & 50.11 & 170.5 \\
\hline$\left(\mathrm{SO}_{4}\right)^{2-}$ & 0.0 & 82.0 & 23.05 & 12.2 \\
\hline Ionic Strength & 0.000 & $0.009 \mathrm{~m}$ & $0.005 \mathrm{~m}$ & $0.007 \mathrm{~m}$ \\
\hline pH & 7.0 & 7.7 & 7.9 & 6.9 \\
\hline
\end{tabular}

\section{PCE sorption}

PCE sorption was determined in matrices of deionized water and test waters from Elizabeth City and Oak Ridge. Sorption isotherms were prepared using initial PCE concentrations of 50 to $200 \mathrm{mg} \mathrm{L}^{-1}$. For some of the experiments ${ }^{14} \mathrm{C}$-labeled PCE was used to simplify quantitation; preliminary experiments showed that this quantitation method yielded the same results as PCE analysis by GC. Duplicate samples and appropriate blanks were prepared for each initial condition. For each initial condition, $10 \mathrm{~mL}$ of the appropriate PCE solution was added to $2.5 \mathrm{~g}$ of SMZ in 10-mL glass crimp-top vials with Teflon-lined septa. All manipulations were done under zero headspace conditions to prevent volatilization of PCE. The vials were shaken for $24 \mathrm{~h}$ at $25^{\circ} \mathrm{C}$ (a period shown in preliminary experiments to be sufficient to attain equilibrium), centrifuged, and the supernatants analyzed via $\mathrm{GC}$, or via liquid scintillation counting in the case of the ${ }^{14} \mathrm{C}$-labeled experiments. Perchloroethylene sorption was determined from the difference between initial and final solution concentrations, with appropriate corrections based on blanks.

\section{Task 1.4 Determine the long-term stability of SMZ}

The major objective under this task was to determine resistance of SMZ to chemical and biological deterioration. Reaction conditions were chosen to simulate aggressive chemical 
environments as well as aerobic and anaerobic environments. We evaluated the stability of SMZ prepared with both HDTMA-Br and HDTMA-Cl, since we found that the HDTMA sorption maximum and the affinity of the resultant SMZ were affected by the HDTMA counterion. The SMZ was prepared as described under Task 1.2 , using ${ }^{14} \mathrm{C}$-labeled HDTMA. The raw zeolite was treated to about $90 \%$ of the sorption maximum with HDTMA (196 mmol kg and $143 \mathrm{mmol} \mathrm{kg}^{-1}$ for HDTMA-Br and HDTMA-Cl, respectively) to prepare SMZ for the stability experiments.

\section{A. Chemical stability}

Two and one-half grams of SMZ was placed in a 50-mL polyallomer centrifuge tube and $15 \mathrm{~mL}$ of the appropriate chemical solution added. The seven different chemical conditions tested are listed in Table 3-2. Each initial condition was prepared in duplicate for SMZ prepared both with HDTMA-Br and HDTMA-Cl. Each mixture was shaken for $24 \mathrm{~h}$ at $25^{\circ} \mathrm{C}$, centrifuged, and $10 \mathrm{~mL}$ of the supernatant removed and analyzed for ${ }^{14} \mathrm{C}$-labeled HDTMA. Ten milliliters of fresh chemical solution was then added, and the equilibration and centrifugation repeated. The entire procedure was repeated a total of eleven times, equivalent to passing approximately 100 pore volumes of the test solution through a bed of SMZ. The cumulative amount of HDTMA removed by the repeated chemical washings was determined by summing the amount removed with each wash.

Table 3- 2 Solutions used to evaluate chemical stability of SMZ.

\begin{tabular}{|c|c|}
\hline Condition Simulated & Chemical Solution \\
\hline Base case & Deionized water \\
\hline Acidic & pH 3 phthalate buffer \\
\hline Basic & pH 10 carbonate buffer \\
\hline Oxidizing & $5 \% \mathrm{H}_{2} \mathrm{O}_{2}$ \\
\hline Reducing & $0.1 M \mathrm{Na}_{2} \mathrm{~S}_{2} \mathrm{O}_{4}$ \\
\hline High ionic strength & $1.0 M \mathrm{CaCl}_{2}$ \\
\hline Cation competition & $1.0 \mathrm{M} \mathrm{CsCl}$ \\
\hline
\end{tabular}

\section{B. Biological stability}

The resistance of SMZ to microbial degradation was determined using microcosms (Fig. 3-1). Each microcosm consisted of a 50-mL Erlenmeyer flask with a hanging cup containing 0.3 $M \mathrm{NaOH}$ solution. Five grams of SMZ prepared with ${ }^{14} \mathrm{C}$-labeled HDTMA was placed in each flask along with nutrient solution and activated sludge from the Socorro sewage treatment plant to provide a diverse community of active microorganisms. The microbial environment in activated sludge is likely more aggressive towards HDTMA degradation than that of most groundwater environments. The ${ }^{14} \mathrm{CO}_{2}$ evolved by microbial degradation of HDTMA was trapped in the $\mathrm{NaOH}$ solution, which was analyzed periodically using liquid scintillation counting.

Six different experimental conditions were evaluated as summarized in Table 3-3. The conditions included aerobic, anaerobic, unsaturated, and water-saturated. We also included two poisoned controls with SMZ and two aqueous solutions of HDTMA without zeolite. Each initial 
condition was prepared in quadruplicate for SMZ prepared with both HDTMA-Br and HDTMACl. The SMZ-free systems used $0.66 \mathrm{mM}$ solutions of HDTMA-Br or $50 \mathrm{mM}$ solutions of HDTMA-Cl. To simulate anaerobic conditions, the headspace of the biometer flask was flushed with $\mathrm{N}_{2}$ gas.

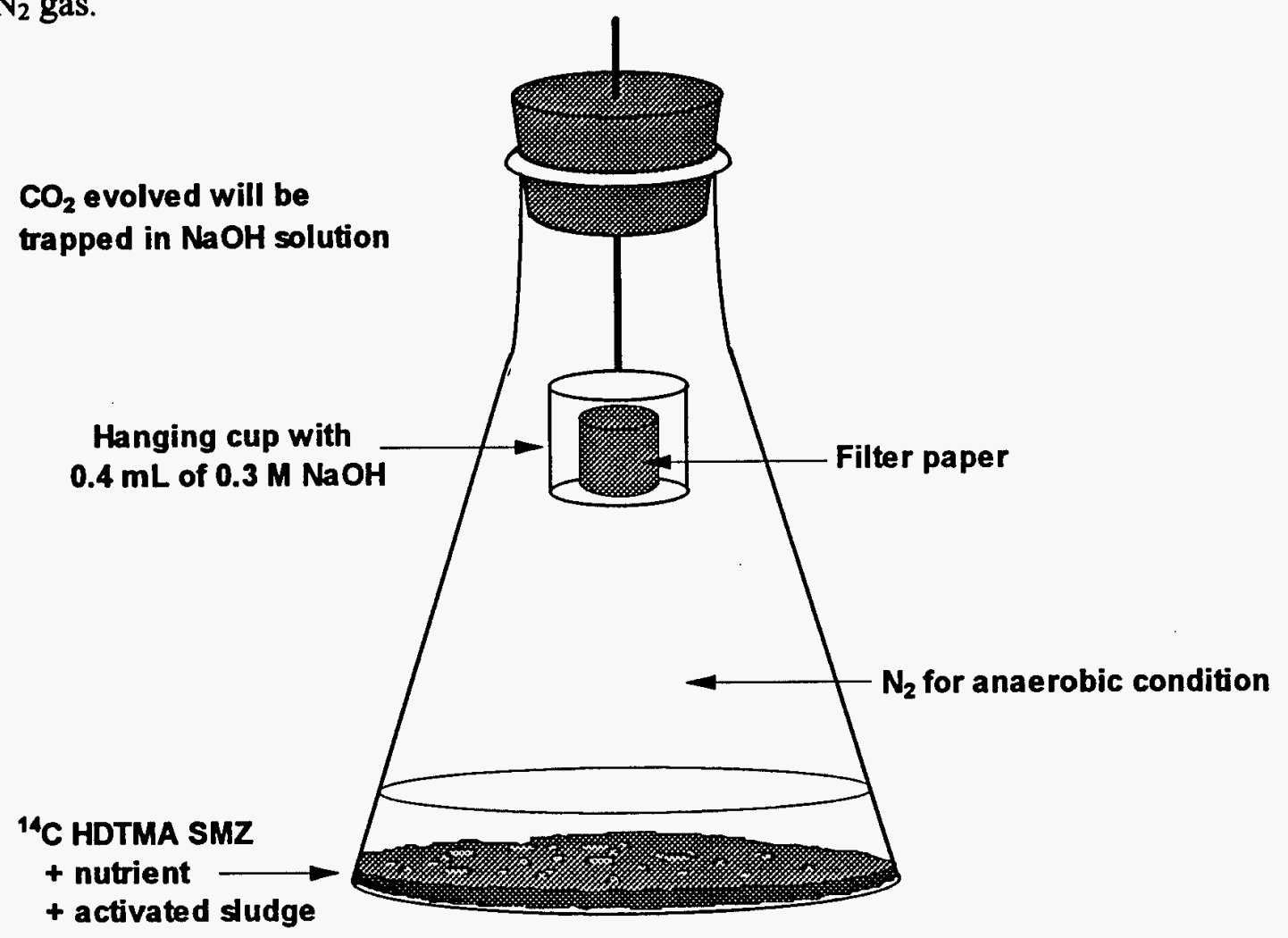

Figure 3- 1 Schematic diagram of microcosm used in biological stability determinations.

Table 3-3 Experimental conditions used to evaluate biological stability of SMZ.

\section{Treatment Experimental Conditions}

A $5 \mathrm{~g} \mathrm{SMZ}$, unsaturated, aerobic

B $5 \mathrm{~g} \mathrm{SMZ}$, unsaturated, poisoned $\left(\mathrm{HgCl}_{2}\right)$

C $5 \mathrm{~mL}$ HDTMA aqueous solution

D $5 \mathrm{~mL}$ HDTMA aqueous solution, poisoned $\left(\mathrm{HgCl}_{2}\right)$

E $5 \mathrm{~g} \mathrm{SMZ}$, saturated, anaerobic $\left(\mathrm{N}_{2}\right)$

F $5 \mathrm{~g} \mathrm{SMZ}$, saturated, aerobic
Nutrient Solution Activated Sludge Added (mL)

Added (mL)

$\begin{array}{ll}2 & 2 \\ 2 & 2 \\ 1 & 1 \\ 1 & 1 \\ 5 & 5 \\ 5 & 5\end{array}$

The $\mathrm{NaOH}$ solution was analyzed for ${ }^{14} \mathrm{C}$ activity every two weeks for a total of 16 weeks for the aerobic treatments and a total of 10 weeks for the anaerobic treatments. After each sampling, the aerobic flasks were flushed with air and the anaerobic flasks were flushed with $\mathrm{N}_{2}$. 
Periodically during this period, samples from the flasks were inoculated onto agar plates to check for the presence of microbial activity.

\section{Advanced microscale characterization of SMZ surface stability}

We used state-of-the-art surface characterization techniques to determine the configuration and stability of HDTMA on the zeolite surface. Untreated zeolite and SMZ were imaged using atomic force microscopy at a resolution of a few nm using a Nanoscope III Scanning Probe Microscope operating a Multi-Mode Atomic Force Microscope (Digital Instruments, Santa Barbara, CA). The thermal stability of the HDTMA on SMZ was determined using high-resolution thermogravimetric analysis with a Hi-Res ${ }^{\text {TM }}$ TGA 2950 (TA Instruments, New Castle, DE). The energetics of HDTMA sorption onto zeolite were determined using a Tronac isothermal solution calorimeter (Tronac, Inc., Orem, UT). The atomic force microscopy and thermogravimetric analysis were performed in collaboration with Dr. Douglas Hunter at the Savannah River Ecology Laboratory (Aiken, SC); more detail on the methodology may be found in Sullivan et al. (1996). The microcalorimetric analyses were performed in collaboration with Dr. J. William Carey of Los Alamos National Laboratory (Los Alamos, NM); more detail on the methodology may be found in Carey et al. (1996).

\section{Task 1.5 Determine the possibility of regenerating SMZ}

The major objective under this task was to determine how to regenerate SMZ saturated with inorganic or organic contaminants. We focused on methods that would allow regeneration of SMZ both ex situ (for instance, when used in a packed bed filtration system) and in situ (for instance, when SMZ is installed as a permeable barrier). We also evaluated the capacity of the regenerated material to sorb chromate and PCE.

\section{A. Chromate}

We tested a variety of chromate extraction reagents based on methods published in the literature (James et al., 1995; Osokov and Bozzelli, 1994; Puls et al., 1994; James and Bartlett, 1983) and also developed our own extractants. The ten extraction reagents we evaluated are listed in Table 3-4. In each case, $2.5 \mathrm{~g}$ of chromate-saturated SMZ was shaken for $24 \mathrm{~h}$ with 20 $\mathrm{mL}$ of extraction reagent, centrifuged, and the supernatant analyzed for extracted chromate. All experiments were performed in duplicate using SMZ prepared with both HDTMA-Br and HDTMA-Cl.

\section{B. PCE}

For regeneration of PCE-saturated SMZ we exploited the volatility of the contaminant. We first saturated SMZ with ${ }^{14} \mathrm{C}$-labeled PCE. To simulate air stripping, we removed excess liquid and passed a gentle stream of air over the surface of a pile of PCE-saturated SMZ for $48 \mathrm{~h}$. We then extracted the SMZ with hexane to solubilize any remaining sorbed PCE and quantified ${ }^{14} \mathrm{C}-\mathrm{PCE}$ in the extract using liquid scintillation counting. We again performed the experiments in duplicate, using SMZ prepared with both HDTMA-Br and HDTMA-Cl. 
Table 3- 4 Extraction reagents tested for regenerating chromate-saturated SMZ.

\begin{tabular}{cl} 
Treatment & Extraction Reagent \\
\cline { 1 - 2 } A & Deionized water \\
B & Deionized water, $95^{\circ} \mathrm{C}$ \\
C & $5 \% \mathrm{H}_{2} \mathrm{O}_{2}$ \\
D & $0.01 \mathrm{M} \mathrm{K}_{2} \mathrm{HPO}_{4} / \mathrm{KH}_{2} \mathrm{PO}_{4}$ \\
E & $0.1 M \mathrm{~K}_{2} \mathrm{HPO}_{4} / \mathrm{KH}_{2} \mathrm{PO}_{4}$ \\
F & $0.01 \mathrm{M} \mathrm{NaOH}$ \\
G & $0.1 M \mathrm{NaOH}$ \\
H & $0.28 \mathrm{M} \mathrm{Na} \mathrm{CO}_{3} / 0.5 M \mathrm{NaOH}$ \\
I & $0.28 M \mathrm{Na}_{2} \mathrm{CO}_{3} / 0.5 M \mathrm{NaOH}, 95^{\circ} \mathrm{C}$ \\
J & $5 \% \mathrm{sodium} \mathrm{dodecyl} \mathrm{sulfate}$
\end{tabular}

Task 1.6 Determine the ability to predict contaminant movement through beds of SMZ

The major objective under this task was to determine if the information generated under Tasks $1.2,1.3$, and 1.4 could be used to predict mobility of contaminants through packed beds of $\mathrm{SMZ}$, as in a permeable barrier. To this end, we designed laboratory column experiments using the transport simulation programs CXTFIT (Toride et al., 1995) to predict mobility of PCE, which follows linear sorption on SMZ, and MOC (Konikow et al., 1994) to predict mobility of chromate, which follows Langmuir-type sorption on SMZ. In each case, the contaminants were in a matrix simulating the composition of the groundwater from Elizabeth City (Table 3-1), which contains a mixed chromate/PCE plume. The experiments were designed to provide the data to test model predictions within one to two months. Chromate and PCE transport experiments were performed separately due to the special precautions required for the volatile PCE.

\section{A. Chromate}

The experimental setup for the chromate transport experiments is shown in Fig. 3-2. An all-plastic system was used to prevent potential interactions of metal fittings with chromate. Specially designed low dead-volume Plexiglas columns from Soil Measurement Systems, Inc., (Tucson, AZ) were used. The columns were $5.0 \mathrm{~cm}$ long with an internal diameter of $5.0 \mathrm{~cm}$. Duplicate columns were packed to uniform bulk densities with SMZ or with untreated zeolite. Dry bulk densities were $1.01 \mathrm{~g} \mathrm{~cm}^{-3}$ (SMZ) and $0.97 \mathrm{~g} \mathrm{~cm}^{-3}$ (untreated zeolite). The packed columns were flushed for $24 \mathrm{~h}$ with $\mathrm{CO}_{2}$ (to provide rapid dissolution of entrapped gas during the subsequent water saturation) and then saturated from the bottom with chromate-free simulated groundwater. Flow was from the bottom up in order to minimize bypass along the column walls. The groundwater flow rate, provided by a reciprocating syringe pump connected to a reservoir, was constant at $375 \mathrm{~mL} \mathrm{~d}^{-1}\left(19.1 \mathrm{~cm} \mathrm{~d}^{-1}\right.$, or 6.6 pore volumes per day). After several days of flow, during which time the composition of the effluent stabilized, $20 \mathrm{mg} \mathrm{L}^{-1}$ chromate and 200 $\mu \mathrm{Ci} \mathrm{L}^{-1}$ tritiated water $\left({ }^{3} \mathrm{H}_{2} \mathrm{O}\right)$ was added to the groundwater and pumping was resumed at the 
same rate. The ${ }^{3} \mathrm{H}_{2} \mathrm{O}$ was used as a nonreactive tracer to determine zeolite hydraulic properties. About 2.5 pore volumes of ${ }^{3} \mathrm{H}_{2} \mathrm{O}$ was added while chromate was added continuously after this point. Beginning with the chromate ${ }^{3} \mathrm{H}_{2} \mathrm{O}$ input, effluent samples were collected every $54 \mathrm{~min}$ using automatic fraction collectors. The effluent samples were analyzed for ${ }^{3} \mathrm{H}_{2} \mathrm{O}$ using liquid scintillation counting and for chromate using HPLC.

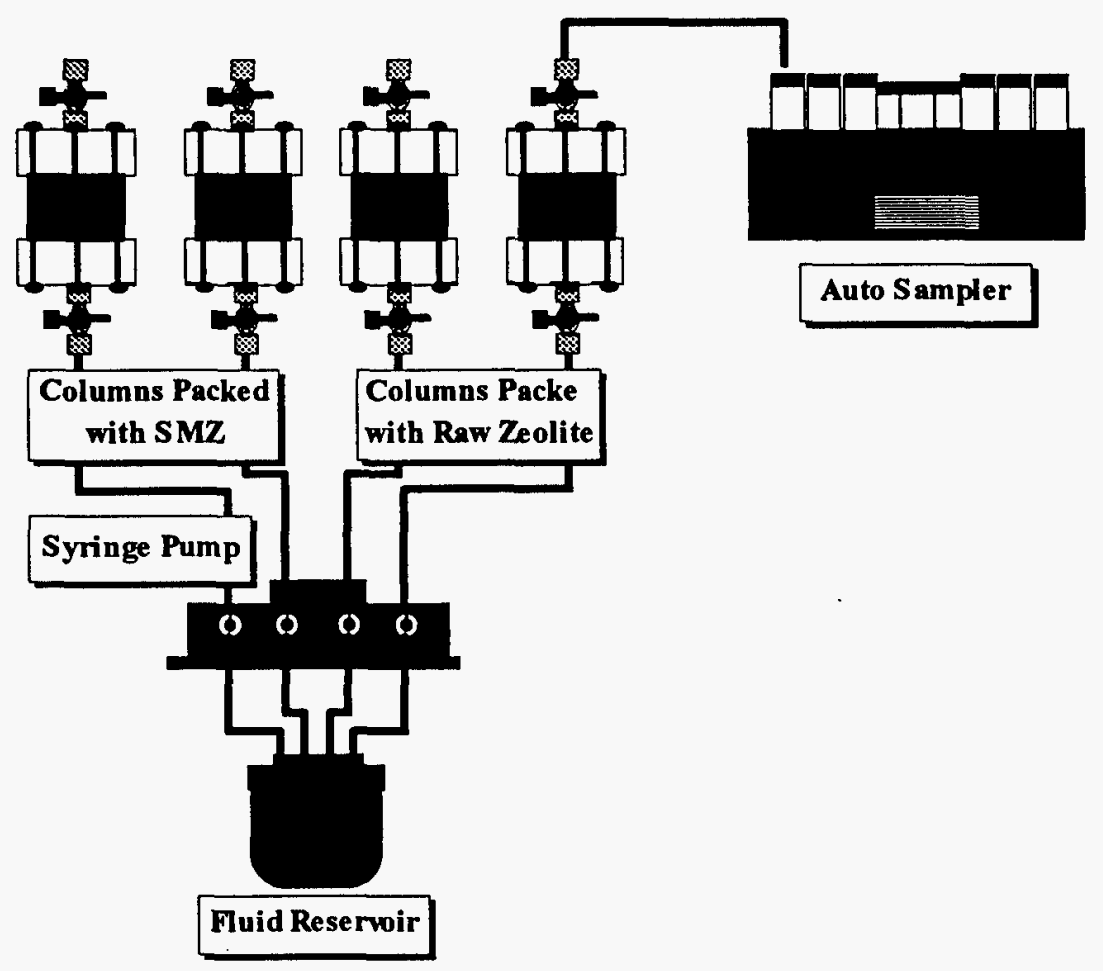

Figure 3- 2 Schematic diagram of laboratory column setup for chromate transport experiments.

\section{B. PCE}

The experimental setup for the PCE transport experiments is shown in Fig. 3-3. A stainless steel and Teflon system was used to prevent sorption of PCE by the apparatus. In addition, all headspace (air) was eliminated from the flow system to prevent PCE mass losses by volatilization. Specially designed low dead-volume stainless steel columns from Soil Measurement Systems, Inc., were used. The columns were $16.5-\mathrm{cm}$ long with an internal diameter of $5.0 \mathrm{~cm}$. Duplicate columns were packed to the same bulk densities as in the chromate transport experiments ( $1.01 \mathrm{~g} \mathrm{~cm}^{-3}$ for $\mathrm{SMZ}, 0.97 \mathrm{~g} \mathrm{~cm}^{-3}$ for untreated zeolite). The packed columns were flushed for $24 \mathrm{~h}$ with $\mathrm{CO}_{2}$ and then saturated from the bottom with PCE-free simulated groundwater. The simulated groundwater from Elizabeth City (Table 3-1) in this case also contained $6.41 \mathrm{mg} \mathrm{L}^{-1}$ chromate, since chromate is a co-contaminant with PCE in this plume. The groundwater flow rate (provided by infusion-type, continuous-feed syringe pumps fitted with 100 -mL gas-tight syringes) was constant at $576 \mathrm{~mL} \mathrm{~d}^{-1}\left(29.4 \mathrm{~cm} \mathrm{~d}^{-1}\right.$, or 3.0 pore volumes per day). The syringes required refilling at approximately 5 -h intervals during the course of the experiment. After several days of flow, during which time the composition of the effluent stabilized, $350 \mu \mathrm{g} \mathrm{L}{ }^{-1}$ of ${ }^{14} \mathrm{C}$-labeled PCE and $200 \mu \mathrm{Ci} \mathrm{L}^{-1}$ of ${ }^{3} \mathrm{H}_{2} \mathrm{O}$ were added to the synthetic groundwater and pumping was resumed at the same rate. The $P C E{ }^{3} \mathrm{H}_{2} \mathrm{O}$ slug was added for 11 
d, after which leaching continued with PCE- and ${ }^{3} \mathrm{H}_{2} \mathrm{O}$-free groundwater. Beginning with the introduction of the $\mathrm{PCE} /{ }^{3} \mathrm{H}_{2} \mathrm{O}$ slug, effluent samples were collected at 1.5 -h intervals by manually filling an air-free syringe at the column outlet. The effluent samples were analyzed for ${ }^{3} \mathrm{H}_{2} \mathrm{O}$ and ${ }^{14} \mathrm{C}-\mathrm{PCE}$ using dual-channel liquid scintillation counting.

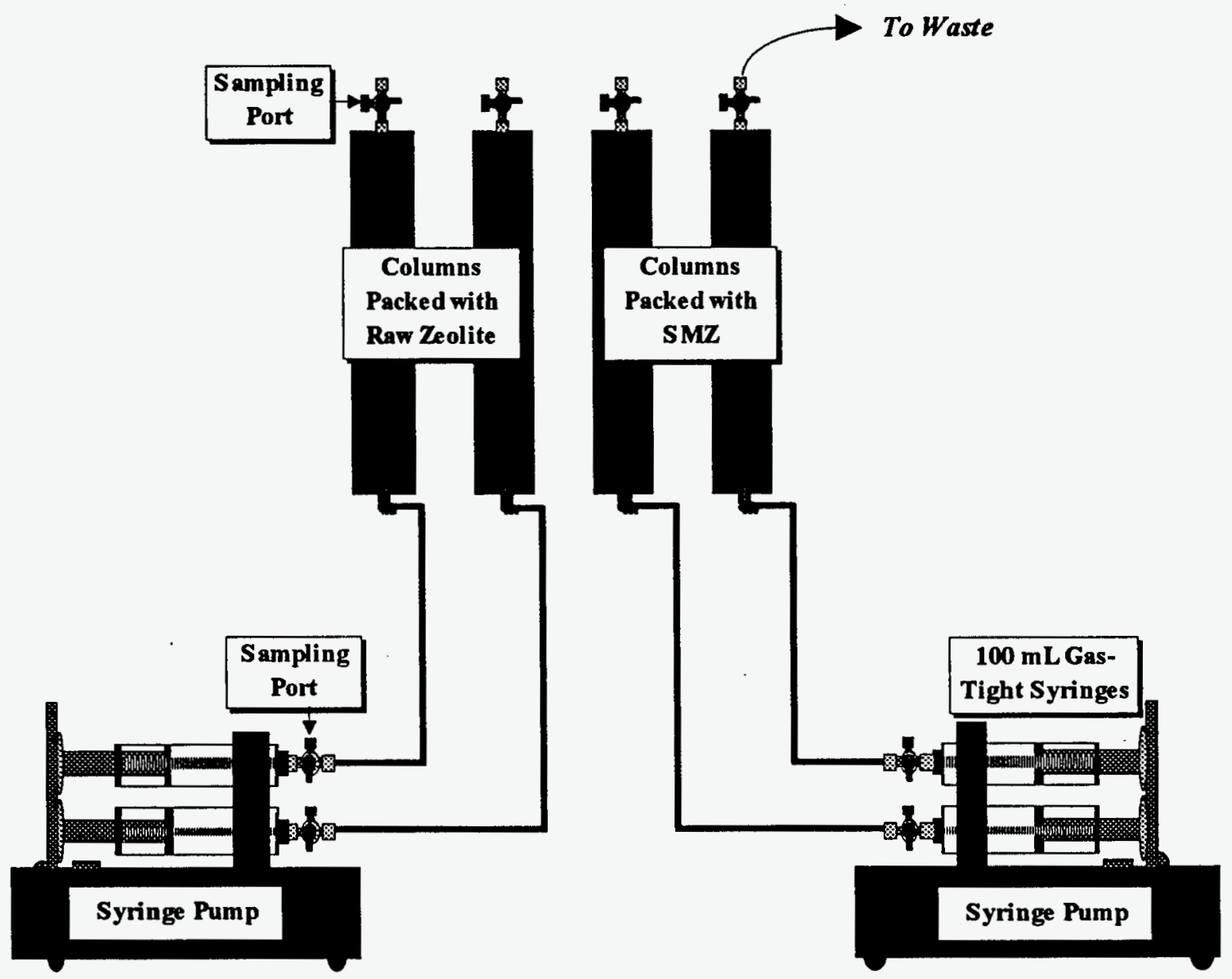

Figure 3- 3 Schematic diagram of laboratory column setup for PCE transport experiments.

\section{Task 1.7. Topical Report}

The major objectives under this task are to summarize the work of Phase I, determine the degree to which the objectives of the designated Phase I tasks have been achieved, draw conclusions from the Phase I results, provide recommendations for future work, and identify possible test-bed facilities for Phase II. 


\subsection{RESULTS AND DISCUSSION}

\section{Task 1.1 Information required for the National Environmental Policy Act}

Approval to proceed with Phase I laboratory experiments was obtained prior to initiation of Phase I activities.

\section{Task 1.2 Develop laboratory production of SMZ}

\section{A. Mineralogical characterization of zeolite}

The mineralogical composition of the raw zeolite is shown in Table 4-1. The material is about $75 \%$ by weight of the zeolite mineral clinoptilolite. Preliminary work (unpublished) showed that clinoptilolite was superior to other zeolites such as chabazite for surfactant modification due to clinoptilolite's relatively high external cation exchange capacity. The St. Cloud zeolite is also low in smectite, which minimizes the shrink/swell behavior of the bulk material. Other commercial sources of clinoptilolite may contain as much as $20 \%$ smectite by weight (Bowman et al., 1995). The other major components of the St. Cloud zeolite, quartz/cristobalite and feldspar, are nonreactive with respect to surfactant modification.

Table 4- 1 Mineralogical analysis of St. Cloud zeolite.

$\begin{array}{cr}\text { Mineral } & \begin{array}{r}\text { Weight } \\ \text { Percent }\end{array} \\ \text { Clinoptilotite } & 74 \pm 4 \\ \text { Smectite } & 5 \pm 2 \\ \text { Quartz }+ & 12 \pm 2 \\ \text { Cristobalite } & \\ \text { Feldspar } & 12 \pm 2 \\ \text { Illite } & 1 \pm 1\end{array}$

The elemental composition of the zeolite before and after surfactant treatment is shown in Table 4-2. The percentage of inorganic components in the SMZ is somewhat reduced compared to the raw zeolite due to the presence of HDTMA in the SMZ. An estimate of the weight percent of HDTMA in the SMZ is given by the $3.4 \%$ difference in the loss on ignition of the SMZ versus the raw zeolite. As shown by Sullivan et al. (1996), this is an underestimate of the actual HDTMA present on the surface, since full decomposition of zeolite-bound HDTMA does not occur below temperatures of $400^{\circ} \mathrm{C}$.

\section{B. Determination of HDTMA sorption by zeolite}

Sorption isotherms for HDTMA-Br, HDTMA-Cl, and $\mathrm{HDTMA}_{-\mathrm{SO}_{4}}$ are shown in Fig. 41. Note that different sorption maxima are obtained with different HDTMA counterions: 210 mmol kg${ }^{-1}$ for HDTMA-Br, $151 \mathrm{mmol} \mathrm{kg}^{-1}$ for HDTMA-Cl, and $132 \mathrm{mmol} \mathrm{kg}^{-1}$ for HDTMA$\mathrm{SO}_{4}$. The data in Fig. 4-1 emphasize the strong effect of counterion on surfactant properties. The 
counterion also affects the sorption properties of SMZ for contaminants (see results under Task 1.3). Sorption of HDTMA by zeolite is rapid. Figure 4-2 shows the sorption of HDTMA-Br as

Table 4- 2 Elemental analysis of St. Cloud zeolite before and after surfactant modification.

\section{Compound \\ $\mathrm{SiO}_{2}$}

$\mathrm{TiO}_{2}$

$\mathrm{Al}_{2} \mathrm{O}_{3}$

$\mathrm{Fe}_{2} \mathrm{O}_{3}$

$\mathrm{MgO}$

$\mathrm{CaO}$

$\mathrm{Na}_{2} \mathrm{O}$

$\mathrm{K}_{2} \mathrm{O}$

Loss on Ignit.

(Trace Ba, Mn, P)
Weight Percent

\begin{tabular}{crr}
\hline Raw Zeolite & SMZ \\
\cline { 1 - 1 } 67.94 & 65.89 \\
0.23 & 0.19 \\
12.06 & 11.52 \\
1.40 & 1.10 \\
1.22 & 1.04 \\
2.87 & 2.67 \\
0.62 & 0.67 \\
2.87 & 2.71 \\
10.51 & 13.79
\end{tabular}

13.79
1.10

1.04

2.67

0.67

271

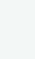




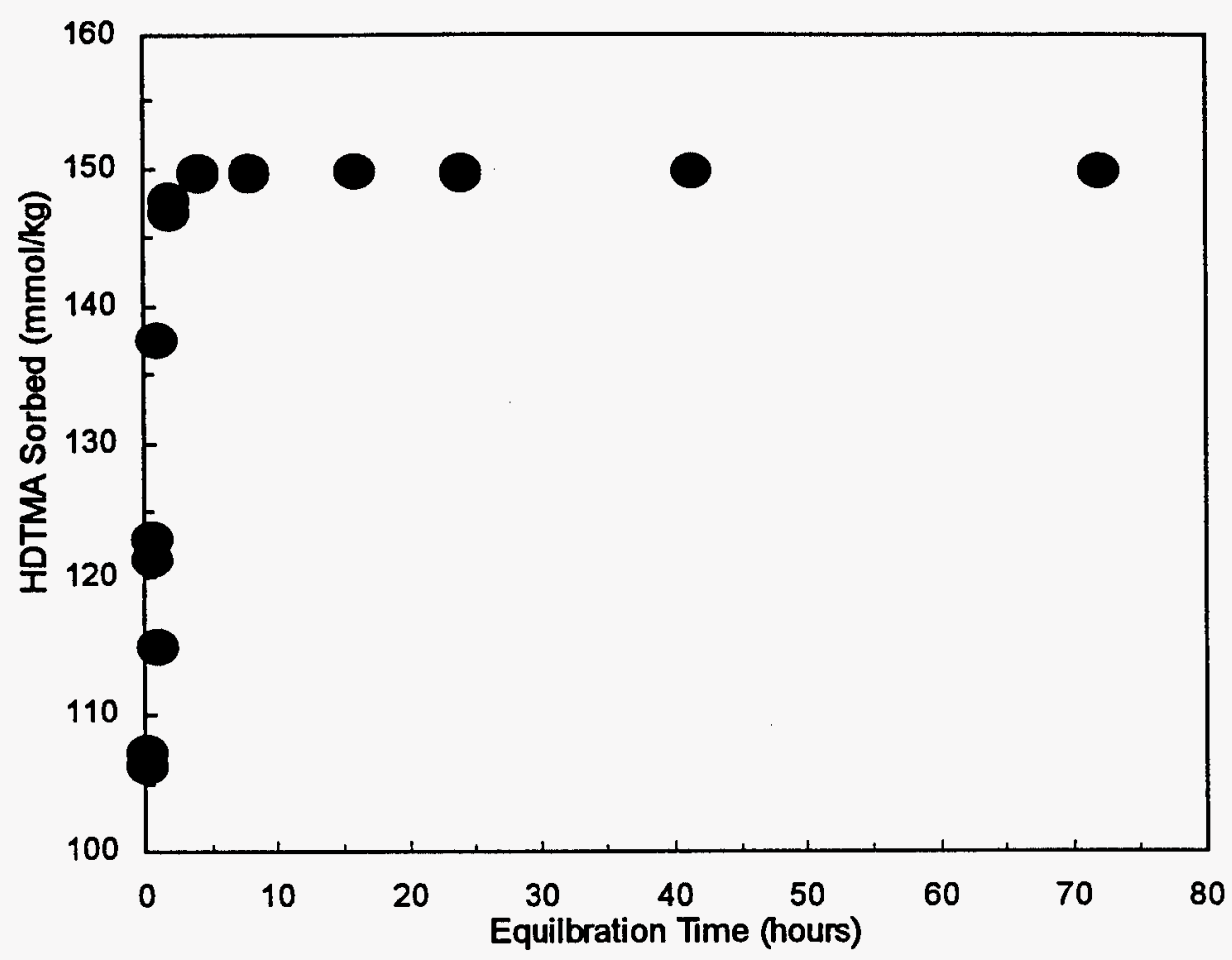

Figure 4- 2 HDTMA-Br sorption by raw zeolite as a function of mixing time. HDTMA-Br added at a rate of $75 \%$ of the sorption maximum.

a function of time. The sorption plateau is reached within several hours of mixing. Parallel experiments showed the same sorption maximum was obtained by mixing solid-form HDTMA-Br with dry raw zeolite, wetting to form a slurry, and then drying. These two results (rapid sorption of HDTMA and the ability to minimize the amount of water added for equilibration) will simplify preparation of the multi-ton quantities of SMZ required for permeable barrier installations.

\section{Preparation of HDTMA-modified zeolite}

The particle size distribution of the SMZ compared to the untreated zeolite is shown in Fig. 4-3. The increased percentage of fines in the SMZ indicates that some particle breakdown occurred during the surfactant treatment due to mechanical abrasion and due to the action of the surfactant on zeolite aggregates. Proper selection of the particle size distribution of the raw zeolite will result in the desired particle size distribution and hydraulic properties of SMZ for a particular application. 


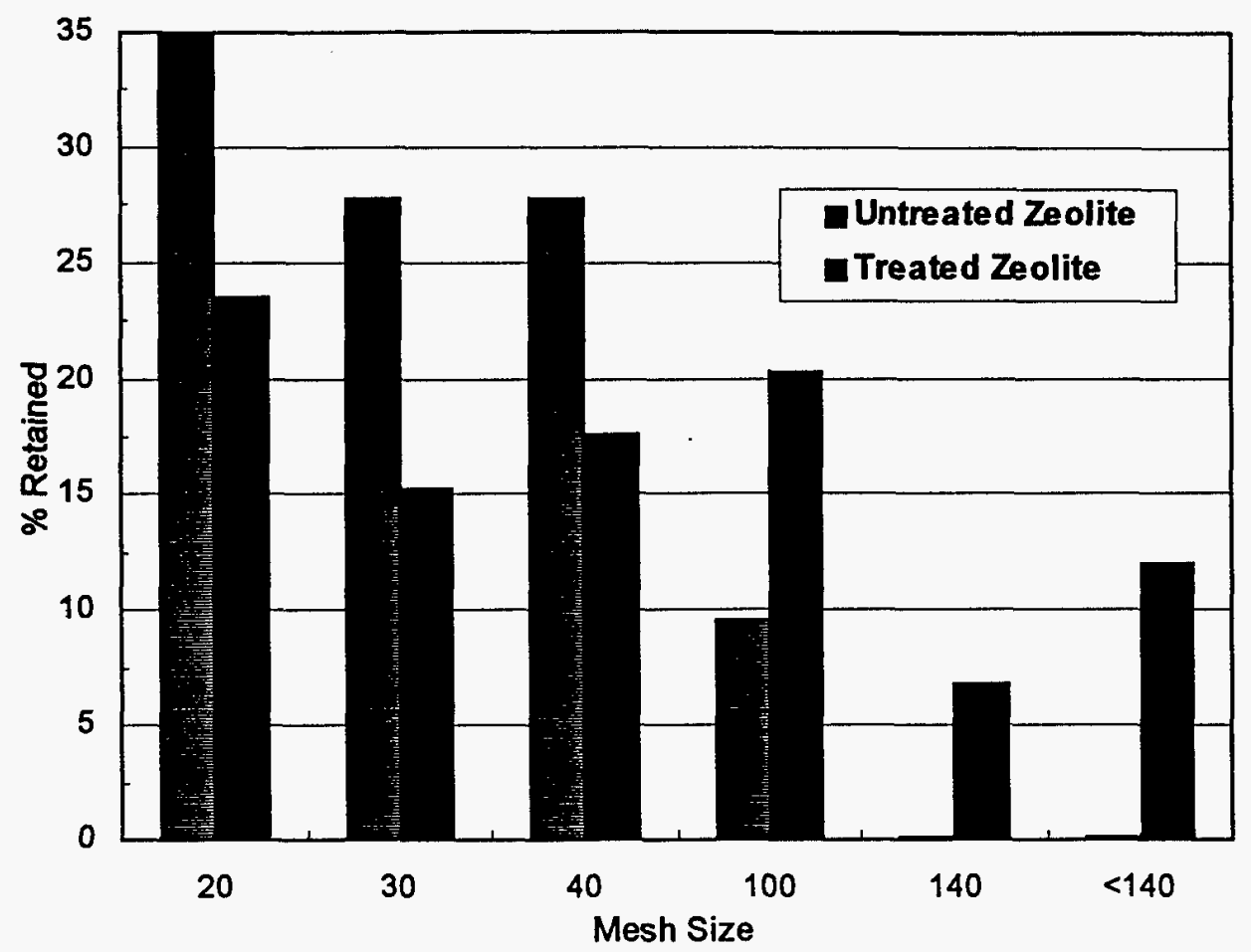

Figure 4- 3 Particle size distribution of SMZ (treated) versus raw (untreated) zeolite.

Task 1.3 Determine effects of site-specific water chemistry on sorption of target compounds

\section{A. Chromate}

The sorption isotherm for chromate dissolved in deionized water is shown in Fig. 4-4. Chromate sorption is well described by the Langmuir isotherm equation, as seen earlier for oxyanion sorption on SMZ (Haggerty and Bowman, 1994). The isotherm shown in Fig. 4-4 is over a large range of chromate concentrations, up to an initial concentration of $800 \mathrm{mg} \mathrm{L}^{-1}$. The maximum chromate saturation of the $\mathrm{SMZ}$ is about $14 \mathrm{mmol} \mathrm{kg}^{-1}\left(1600 \mathrm{mg} \mathrm{kg}^{-1}\right)$. No chromate was sorbed by untreated zeolite.

Figure 4-5 shows the sorption isotherms for chromate dissolved in the simulated groundwaters from Elizabeth City and Hanford over a lower range of chromate concentrations more typical of contaminated groundwaters. At these lower chromate concentrations, the Langmuir isotherm is essentially linear (Fetter, 1993). In this concentration range SMZ effectively removed $90-95 \%$ of the chromate from each water. Sorption from Hanford water was about the same as from DI water, but chromate sorption from Elizabeth City water was lower. The lower chromate sorption is consistent with the relatively high sulfate concentration of $82 \mathrm{mg}$ $\mathrm{L}^{-1}$ in the Elizabeth City water (Table 3-1). Preliminary experiments showed that, while SMZ is highly selective for chromate sorption, high levels of sulfate can compete. Thus the use of SMZ as a permeable barrier may be limited if the groundwater contains high levels of sulfate. In contrast, preliminary testing of waters with high levels of other common groundwater anions such as $\mathrm{Cl}^{-}$and $\mathrm{HCO}_{3}{ }^{-}$has shown little competitive effect on chromate sorption. 


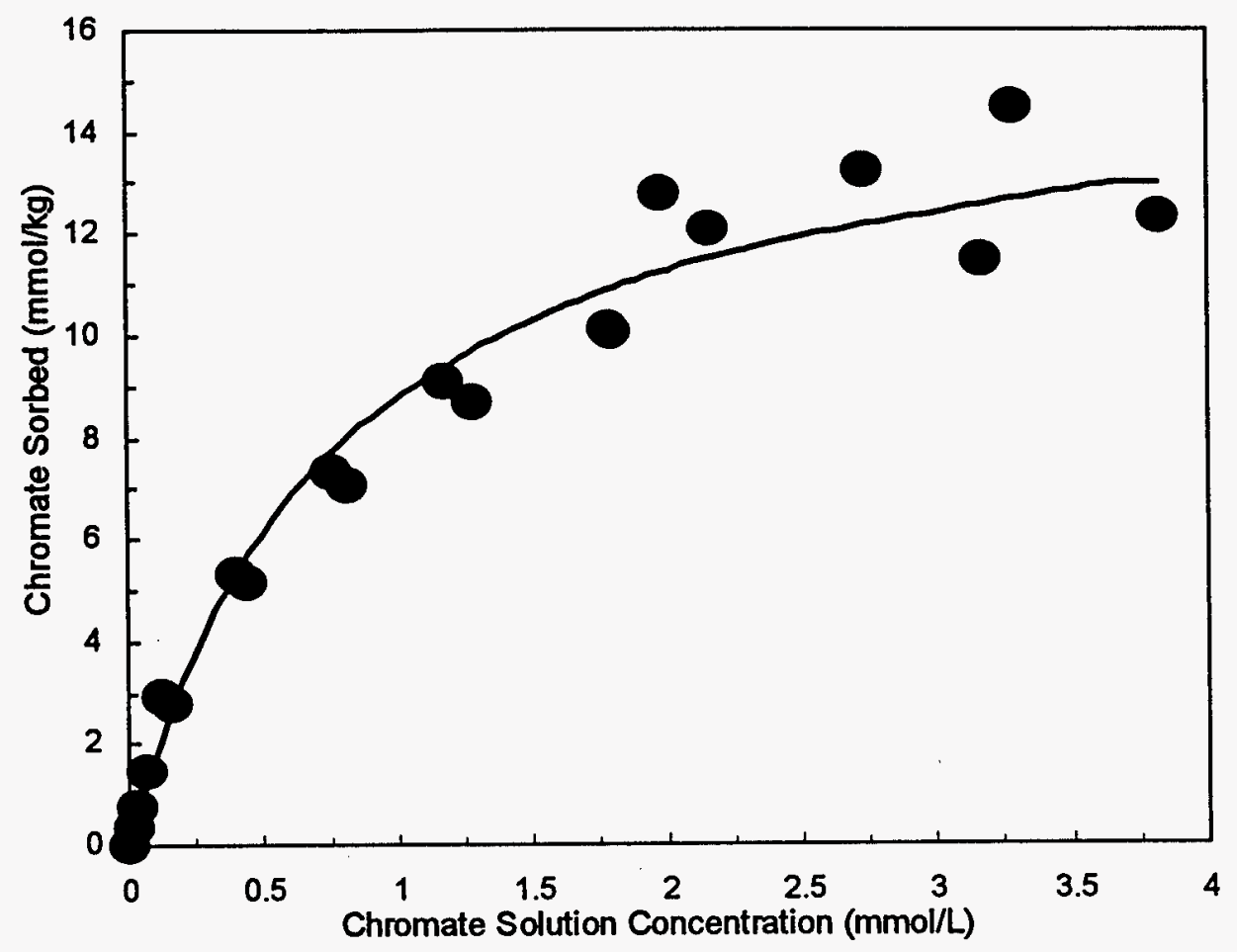

Figure 4- 4 Sorption isotherm for chromate dissolved in deionized water. The solid line is a Langmuir isotherm fit to the data.

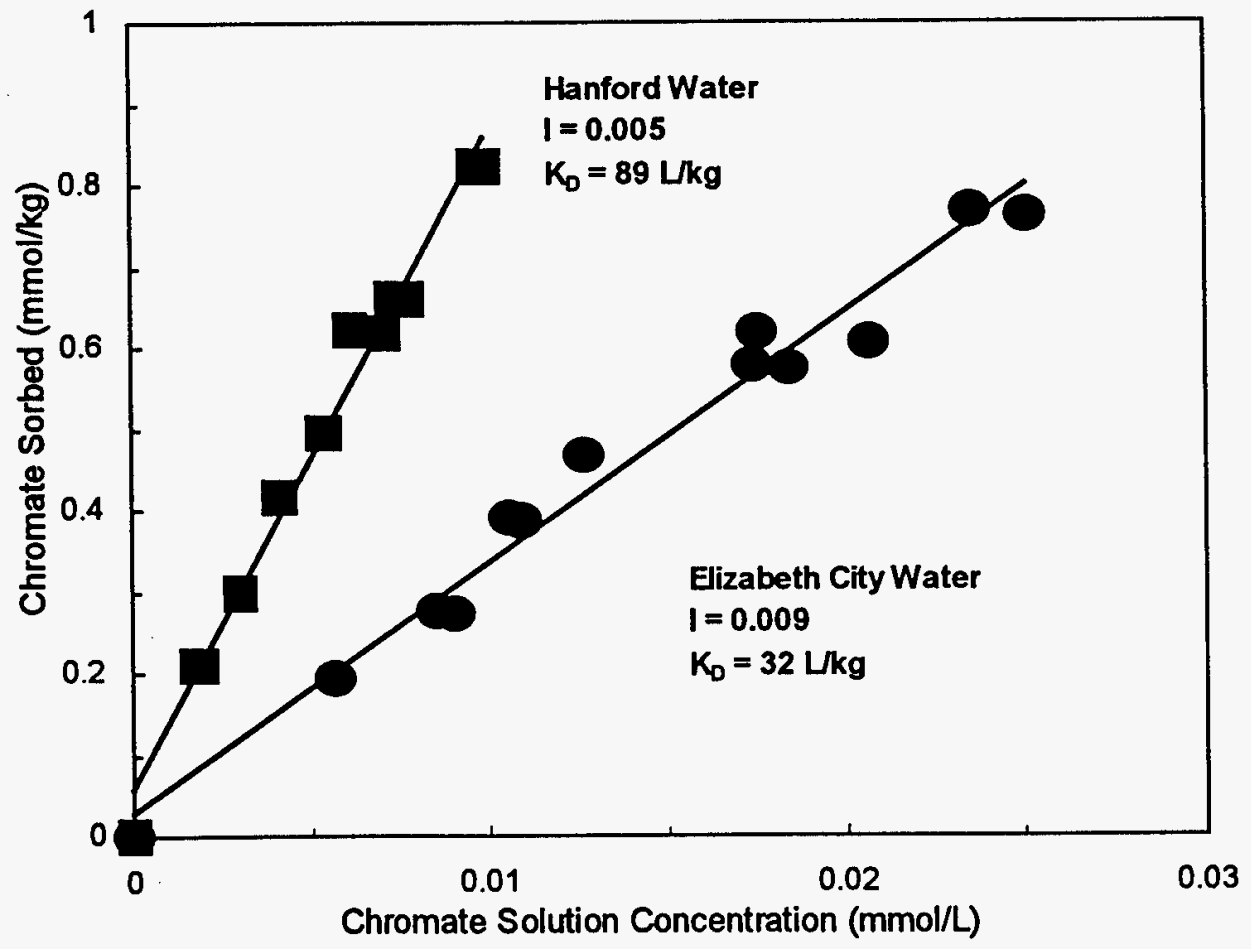

Figure 4- 5 Sorption isotherms for chromate dissolved in waters from Elizabeth City, NC, and Hanford, WA. 
The HDTMA counterion has a strong effect on chromate sorption. Figure 4-6 shows chromate sorption by SMZ prepared with HDTMA-Br, HDTMA-Cl, and HDTMA-HSO ${ }_{4}$. In each case the raw zeolite had been treated up to the HDTMA sorption maximum (Fig. 4-1). Note in Fig. 4-6 that the greatest chromate sorption is shown by SMZ prepared with HDTMA-HSO, followed by SMZ prepared with HDTMA-Cl and HDTMA-Br. The observed order of chromate sorption is exactly the reverse order of the HDTMA sorption maxima for the different

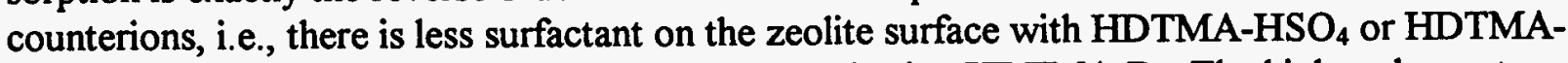
$\mathrm{Cl}$, but they sorb more chromate than SMZ prepared using HDTMA-Br. The higher chromate sorption at lower levels of HDTMA loading has implications for the economics of SMZ production and use for specific remediation problems, as described later in this report.

Chromate sorption increases with HDTMA loading on the zeolite surface. Figures 4-7 and 4-8 show chromate sorption by SMZ prepared with HDTMA-Br and HDTMA-Cl, respectively, as a function of HDTMA initially sorbed on the raw zeolite. Thus maximum chromate retention by SMZ will be achieved by adding HDTMA up to the sorption plateau for the specific HDTMA counterion (Fig. 4-1).

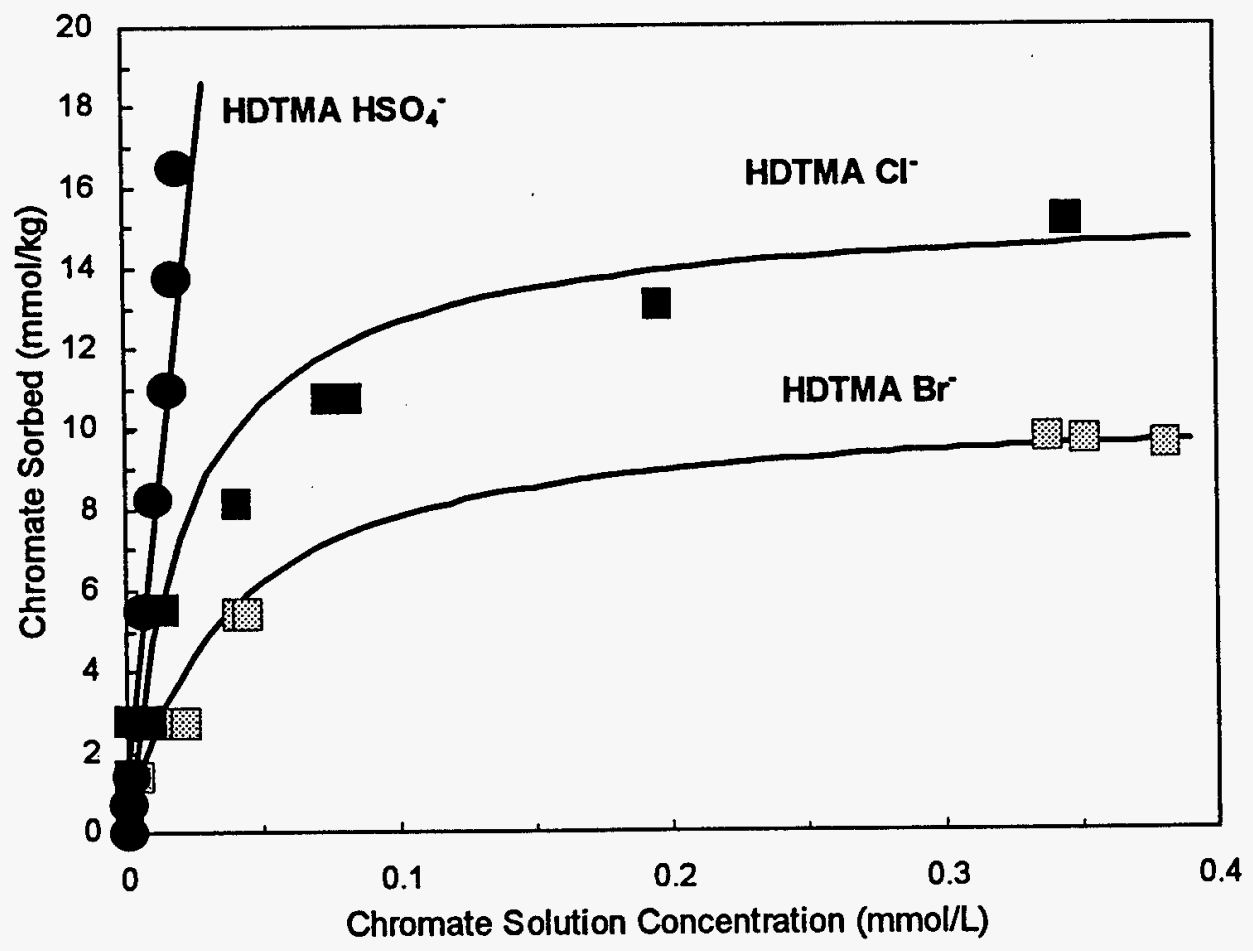

Figure 4- 6 Chromate sorption by SMZ prepared using HDTMA-Br, HDTMA-Cl, or HDTMA-HSO 4 


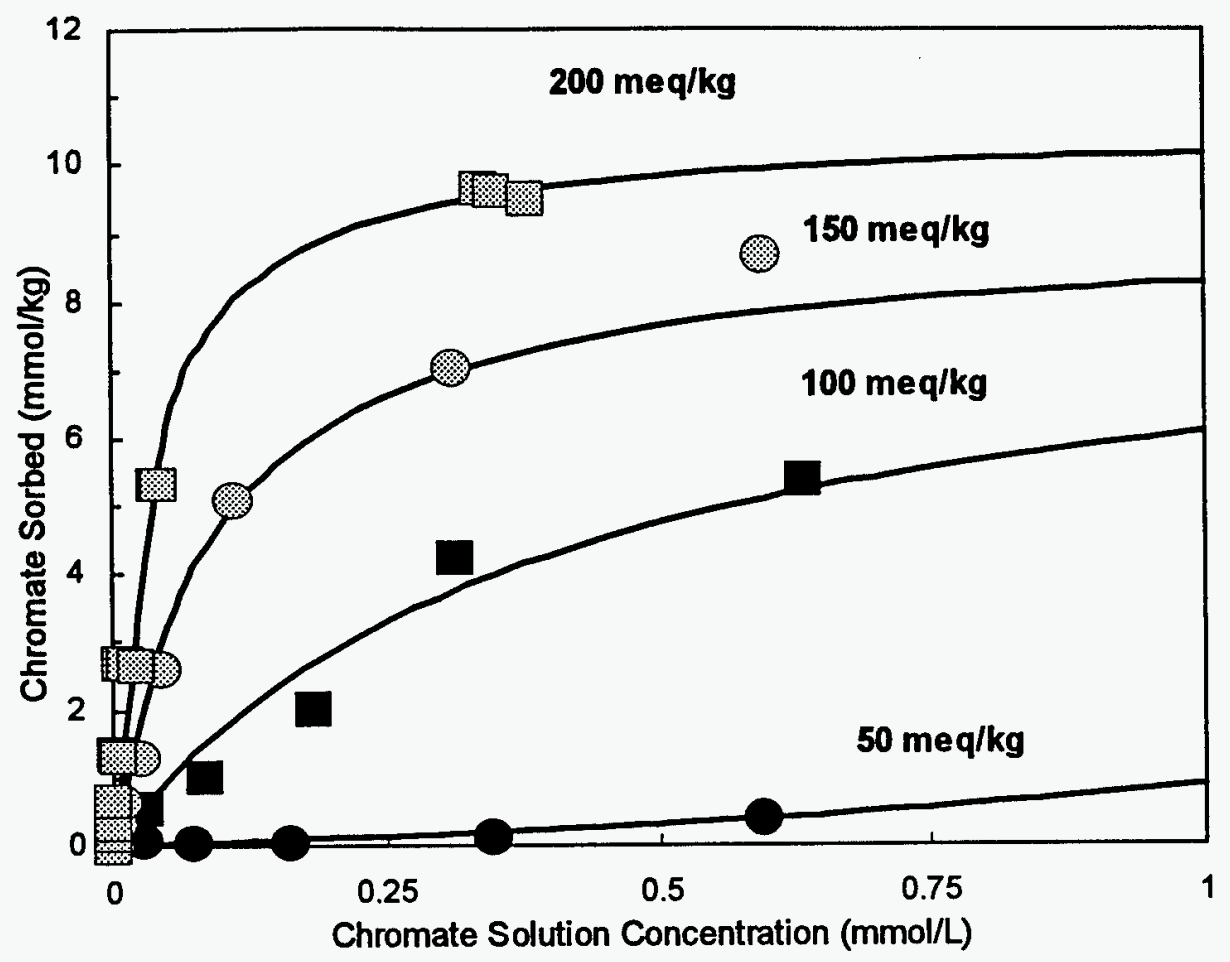

Figure 4- 7 Chromate sorption by SMZ as a function of surface coverage for HDTMA-Br. Numbers on lines indicate the amount of HDTMA on the zeolite surface.

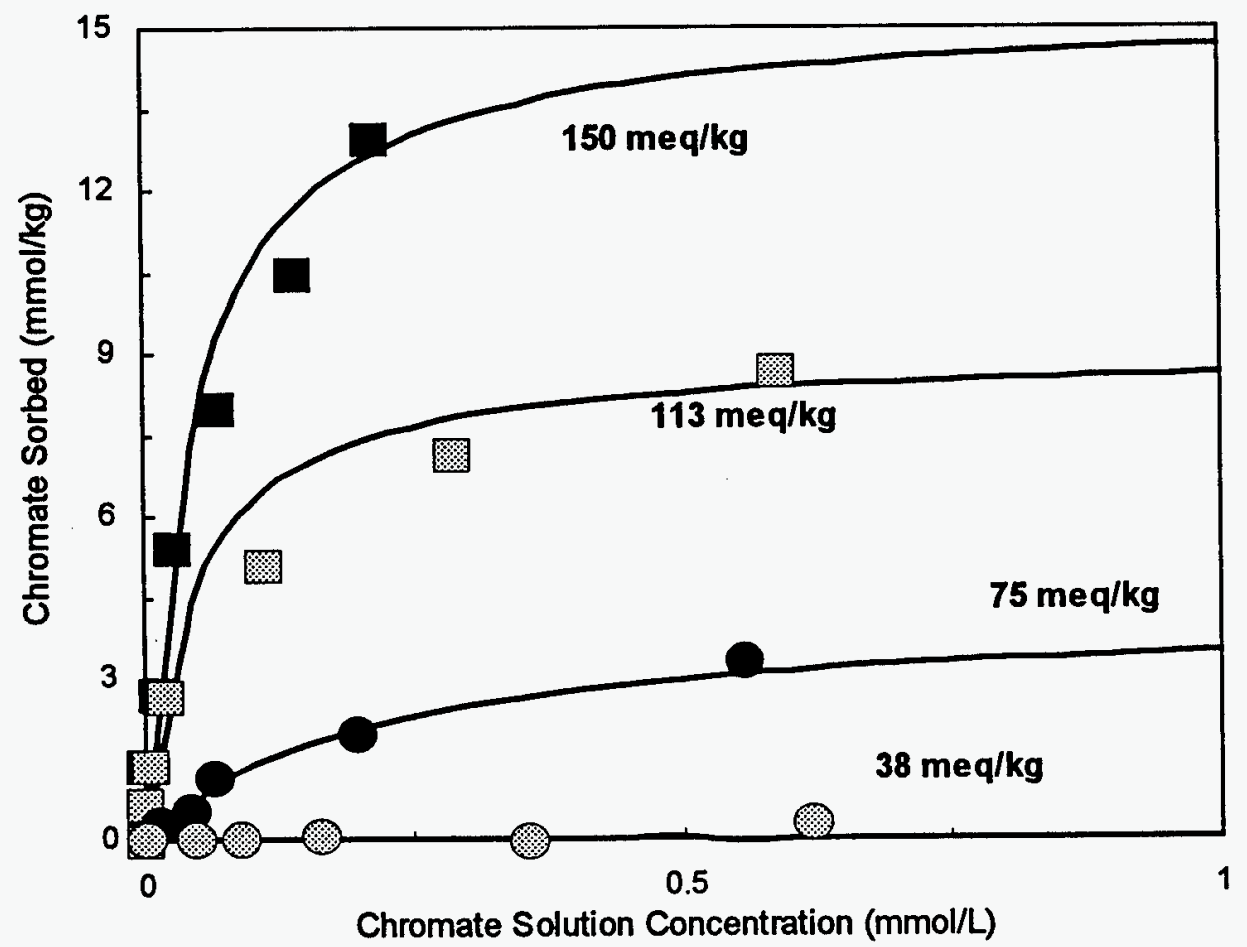

Figure 4- 8 Chromate sorption by SMZ as a function of surface coverage for HDTMA-CI. Numbers on lines indicate the amount of HDTMA on the zeolite surface. 


\section{B. PCE}

Sorption isotherms for PCE dissolved in deionized water and waters from Elizabeth City and Oak Ridge are shown in Fig. 4-9. All the isotherms are linear, as expected for sorption of a nonpolar organic by SMZ (Neel and Bowman, 1992; Bowman et al., 1995). Sorption of PCE was greatest from deionized water, followed by sorption from Oak Ridge and Elizabeth City waters. At least $85 \%$ of the PCE was removed from each water by the SMZ. No PCE was removed by raw zeolite. The effectiveness of PCE removal (as indicated by the $K_{D}$ for each isotherm) was related to the ionic strength of the water, with the least sorption from the higher ionic strength Elizabeth City water (Table 3-1). This trend suggests that dissolved organic removal by SMZ will be reduced in high ionic strength waters such as brines.

The HDTMA counterion has a relatively small effect on PCE sorption. Figure 4-10 shows PCE sorption by SMZ prepared with HDTMA-Br and HDTMA-Cl. In each case the raw zeolite had been treated up to the HDTMA sorption maximum (Fig. 4-1). Although SMZ prepared with HDTMA-Cl uses less surfactant than SMZ prepared with HDTMA-Br, the former is at least as effective in removing PCE from water. Figure 4-11 shows that near-maximum PCE sorption is obtained at about half the maximum HDTMA surface coverage . These results suggest that if SMZ is used primarily to remove organic contaminants from water, a lower HDTMA surface coverage may be used, thereby lowering the cost of the SMZ.

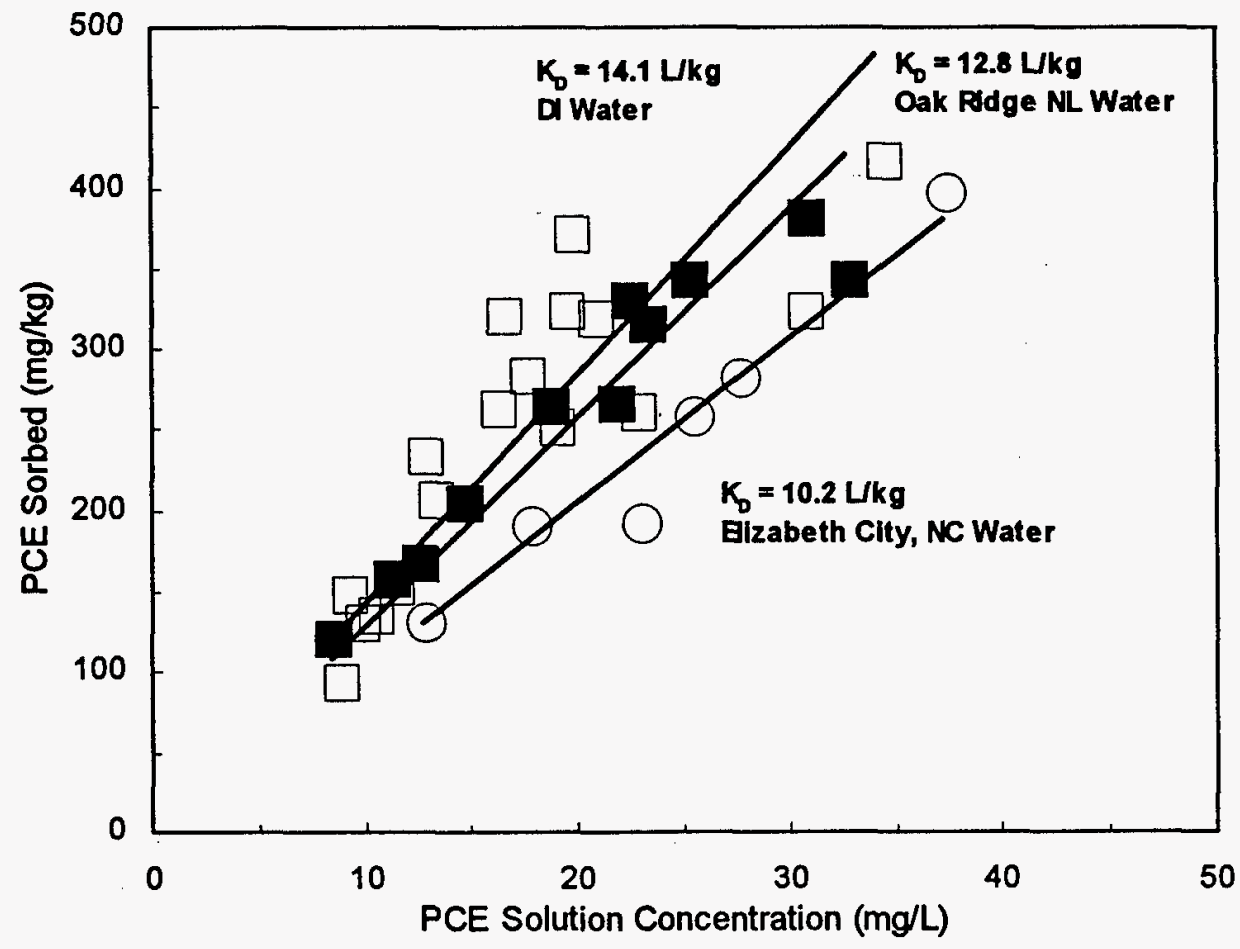

Figure 4- 9 Sorption isotherms for PCE dissolved in deionized water, and in waters from Elizabeth City, NC, and Oak Ridge, TN. 


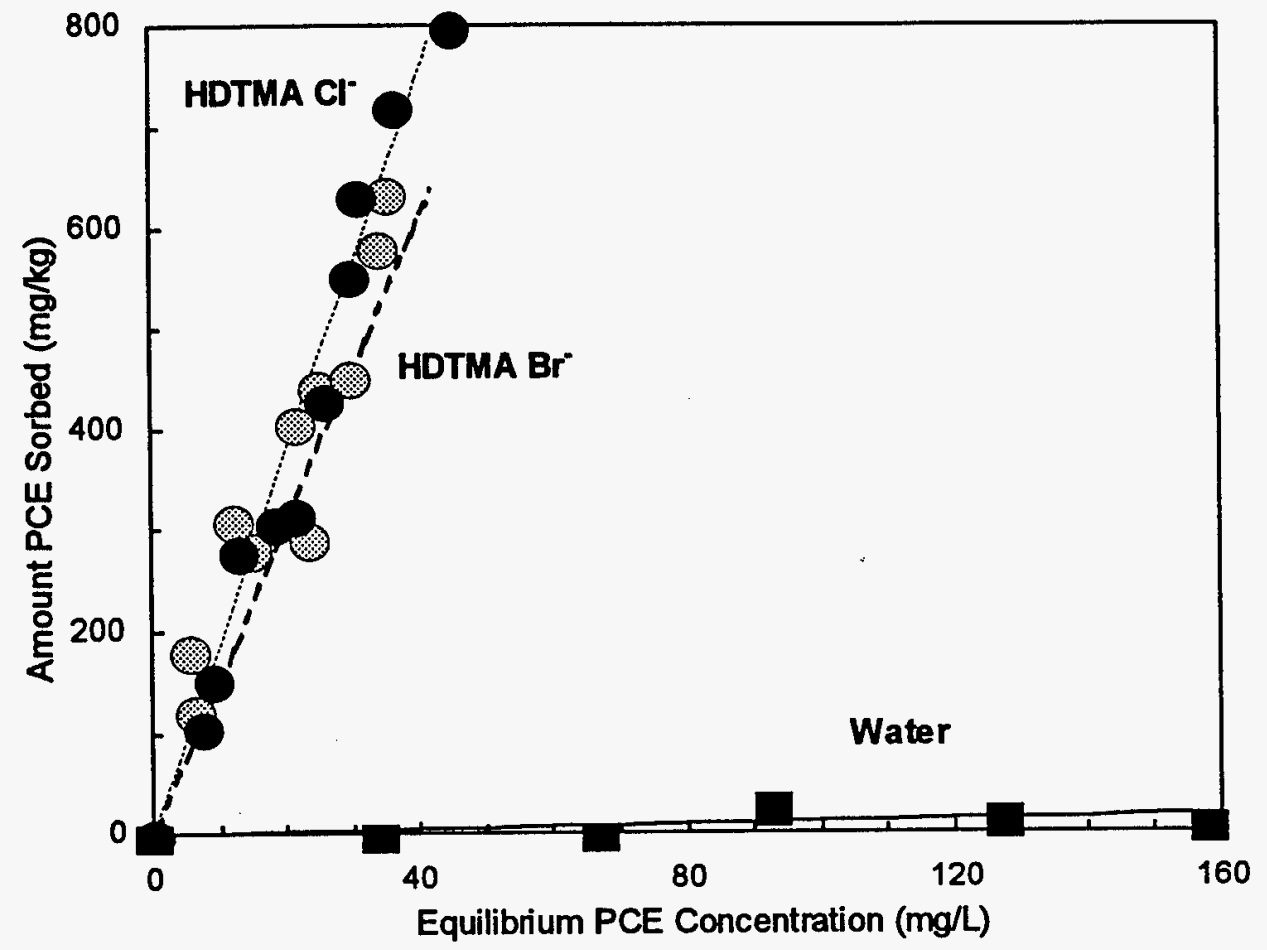

Figure 4- 10 PCE sorption by SMZ prepared using HDTMA-Br or HDTMA-Cl.

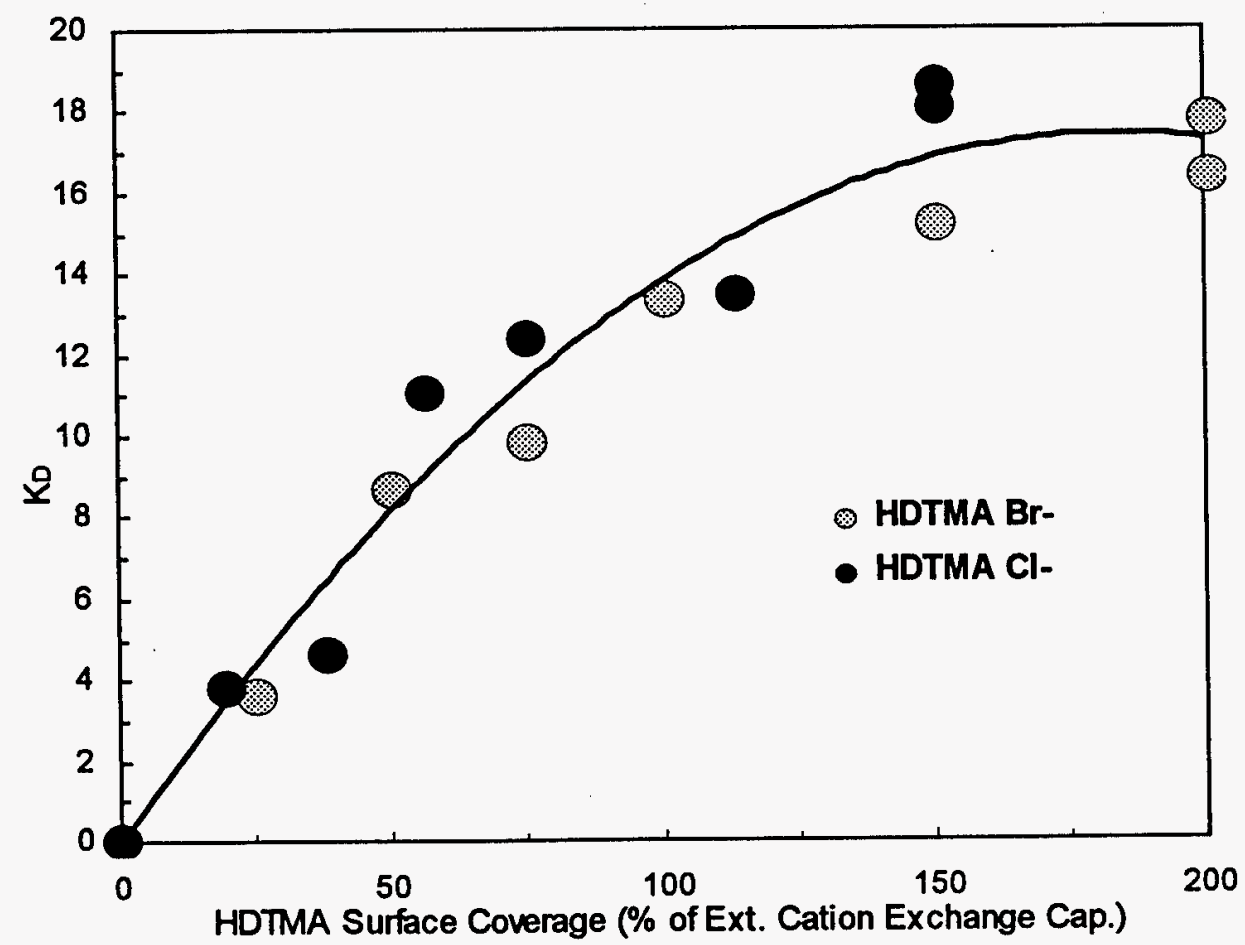

Figure 4- 11 PCE sorption by SMZ as a function of HDTMA surface coverage for HDTMA-Br and HDTMA-Cl. $K_{\mathrm{D}}$ is the slope of the linear sorption isotherm at each loading rate. 


\section{Task 1.4 Determine the long-term stability of SMZ}

\section{A. Chemical stability}

The results of the chemical stability tests are shown in Fig. 4-12. Results were similar whether the SMZ was prepared with HDTMA-Br or HDTMA-Cl. More than $90 \%$ of the original surfactant treatment remained on the zeolite surface after washing with 100 pore volumes of 0.1 $M \mathrm{Na}_{2} \mathrm{~S}_{2} \mathrm{O}_{4}, 1.0 \mathrm{M} \mathrm{CaCl}_{2}$, pH 3 buffer, or $\mathrm{pH} 10$ buffer (simulating reducing, high ionic strength, acidic, and basic groundwater conditions, respectively). Washing SMZ with 100 pore volumes of deionized water or $5 \% \mathrm{H}_{2} \mathrm{O}_{2}$, simulating low ionic strength and oxidizing conditions, removed $15-20 \%$ of the bound surfactant. It is likely that the washoff in $\mathrm{H}_{2} \mathrm{O}_{2}$ was also a result of the low ionic strength of this reagent, rather than chemical oxidation. Low ionic strengths destabilize surfactant systems whether the surfactant is in solution or sorbed to solid surfaces.

The $1.0 \mathrm{M} \mathrm{CsCl}$ solution was the most effective in removing surfactant from $\mathrm{SMZ}$, washing off $30-50 \%$ of the original bound surfactant after 100 pore volumes. Cesium has a high selectivity for cation exchange on zeolites and clays; fortunately, Cs levels in groundwaters are orders of magnitude lower than the $1.0 \mathrm{M}$ Cs used here, and even waters highly contaminated with ${ }^{137} \mathrm{Cs}$ have sub- $\mu M$ concentrations of Cs. Thus, this worst-case washoff scenario will never be encountered in contaminated groundwaters. Extremely contaminated groundwaters are more likely to resemble the waters shown in the left half of Fig. 4-12, which shows minor losses of HDTMA after extensive washing. We conclude that HDTMA washoff is not likely to be a problem if SMZ is installed as a permeable barrier. Furthermore, any minor amounts of HDTMA released from the zeolite would be rapidly sorbed by clays and other cation-sorbing minerals downgradient of the barrier.

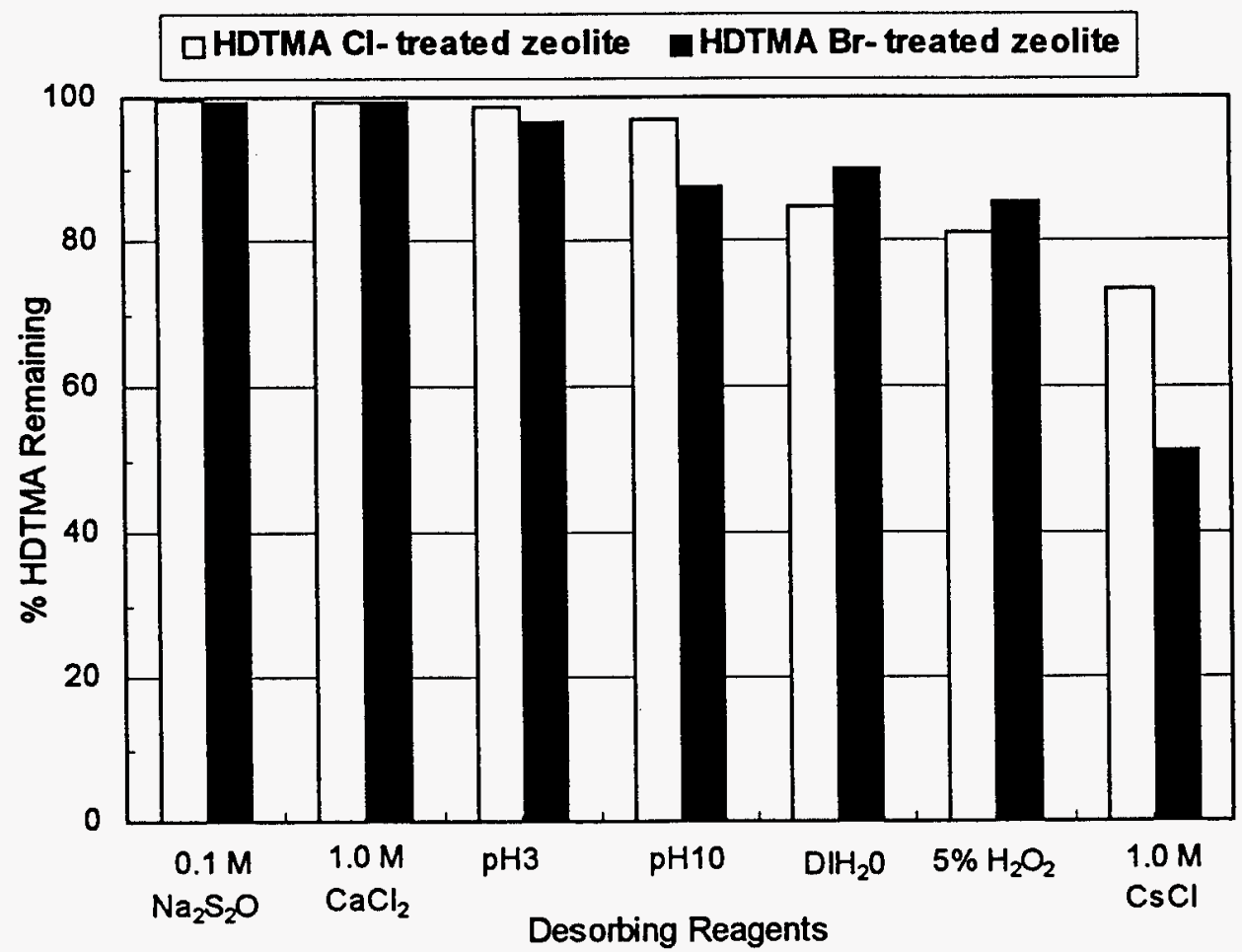

Figure 4- 12 Percentage of original HDTMA remaining on SMZ after washing with 100 pore volumes of various reagents. 


\section{B. Biological stability}

The results of the biological stability tests are shown in Fig. 4-13. The aerobic and anaerobic treatments (designated A-F) are defined in Table 3-3. Note that the ordinate in Fig. 413 ranges from $95-100 \%$. The maximum HDTMA loss (as determined by evolution of ${ }^{14} \mathrm{CO}_{2}$ ) was $4 \%$ from a single replicate under unsaturated, aerobic conditions (Treatment A). Most of the individual replicates retained more than $98 \%$ of the original HDTMA after incubation for 14 weeks (aerobic conditions) or 8 weeks (anaerobic conditions). We conclude that microbial breakdown of HDTMA under field conditions in a permeable barrier are likely to be negligible. Our results concur with those of Nye et al. (1994) who found that HDTMA sorbed on smectite was resistant to microbial breakdown.

Inoculation of microcosm contents on agar plates showed that viable organisms were present in all SMZ treatments at all times. Consistent with the known biocidal behavior of aqueous HDTMA, little microbial activity was noted in the SMZ-free treatments (Treatments C and D). Sorption of HDTMA on the zeolite appears to render it innocuous with respect to microbial activity. We thus conclude that SMZ will have little if any deleterious effect on native microbial communities. Furthermore, biological treatments such as nutrient-stimulated biodegradation could be effectively combined with $\mathrm{SMZ}$ permeable barriers to provide destruction of organic contaminants in situ.

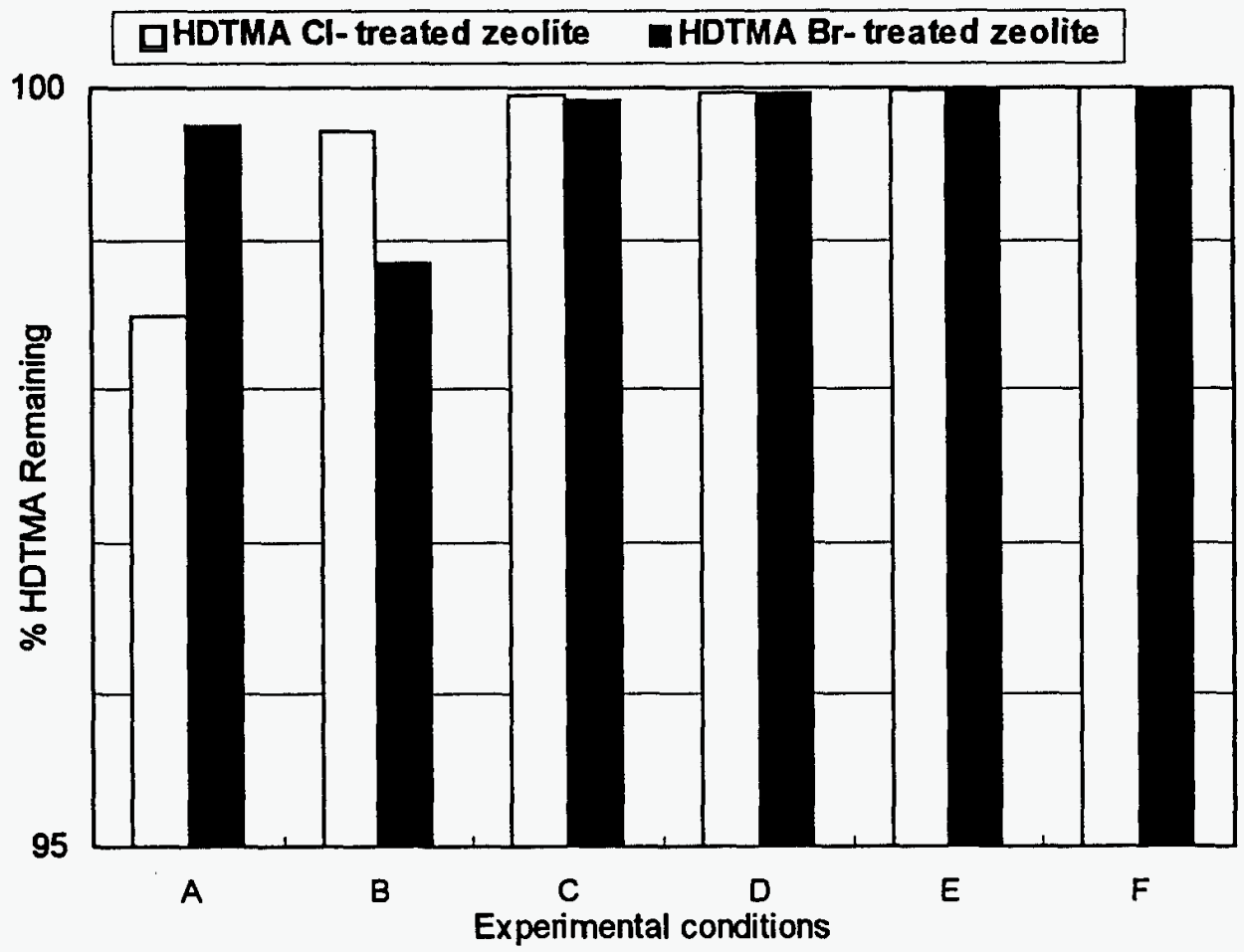

Figure 4- 13 Percentage of original HDTMA remaining on SMZ after incubation with activated sludge under aerobic (14 weeks) and anaerobic (8 weeks) conditions. 


\section{Advanced microscale characterization of SMZ surface stability}

The atomic force microscopy images showed extensive tailgroup interactions among surfactant molecules on the zeolite surface even at coverages less than the external cation exchange capacity (Sullivan et al., 1996). The stabilization provided by these interactions explains the resistance of SMZ to chemical and biological breakdown. Similarly, the thermogravimetric analyses showed that HDTMA sorbed on the zeolite surface was more resistant to degradation at high temperatures than was pure HDTMA (Fig. 4-14). While HDTMA-Br decomposed at $232^{\circ}$ $\mathrm{C}, \mathrm{HDTMA}$ sorbed on zeolite at low surface coverages was stable up to $334^{\circ} \mathrm{C}$ (Sullivan et al., 1996).

Calorimetric analyses showed that the enthalpy of sorption is dependent upon surfactant chain length. Short-chain surfactants such as tetraethylammonium showed a small positive enthalpy of sorption, while HDTMA showed a negative enthalpy of sorption of about $-10 \mathrm{~J} \mathrm{meq}^{-1}$ (Fig. 4-15). The enthalpy of HDTMA sorption was similar whether the HDTMA was sorbed as monomers or as micelles. This negative enthalpy of sorption is further evidence that strong bonds are formed between HDTMA and the zeolite surface, resulting in chemical stability of SMZ. 


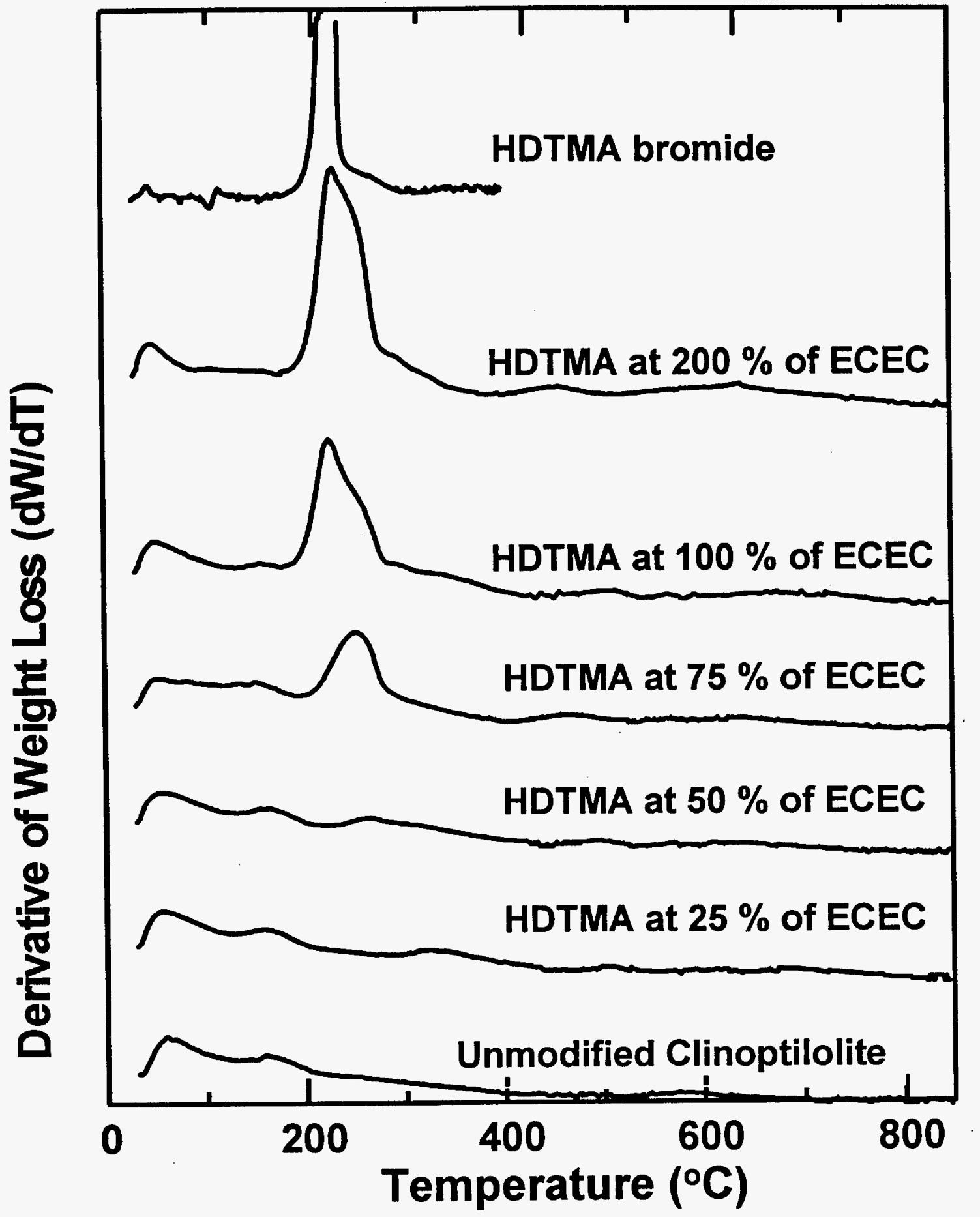

Figure 4- 14 Derivative weight loss curves for thermogravimetric analysis of SMZ at different HDTMA surface coverages (\% of ECEC, the external cation exchange capacity). 


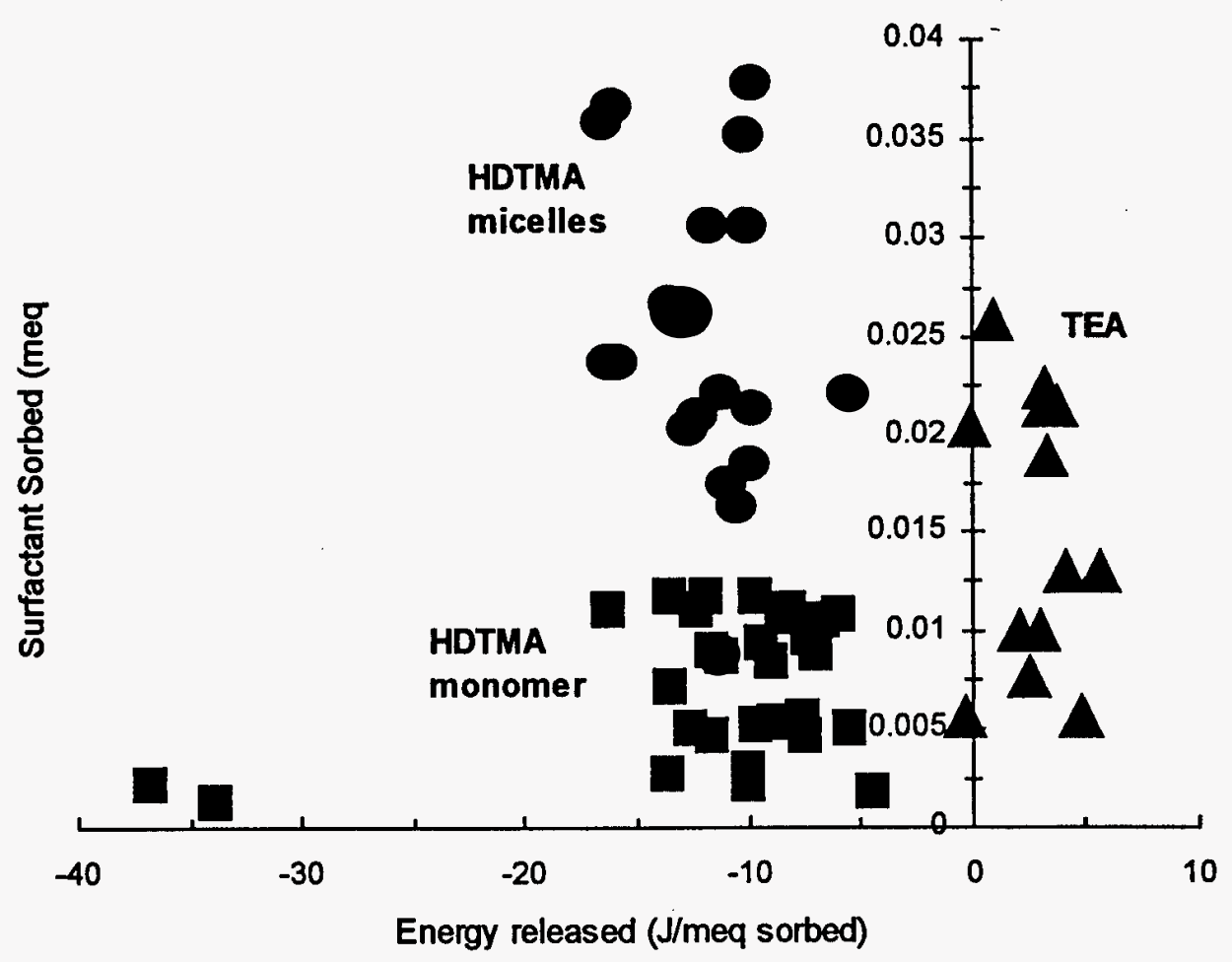

Figure 4- 15 Enthalpy changes associated with sorption of HDTMA and tetraethylammonium (TEA) on raw zeolite.

Task 1.5 Determine the possibility of regenerating SMZ

\section{A. Chromate}

Figure 4-16 shows the efficiency of various reagents for extracting chromate from chromate-saturated SMZ. Again, there was relatively little difference in extraction efficiency whether HDTMA-Br or HDTMA-Cl was used to prepare the SMZ. The most effective extracting reagents were $\mathrm{Na}_{2} \mathrm{CO}_{3} / \mathrm{NaOH}$ and sodium dodecyl sulfate, which removed $70-90 \%$ of the bound chromate in a single wash. The regeneration is apparently due to the ability of $\mathrm{CO}_{3}{ }^{2-}$ and dodecyl sulfate to compete effectively with chromate for exchange sites on the SMZ. The $\mathrm{Na}_{2} \mathrm{CO}_{3} / \mathrm{NaOH}$ mixture is an inexpensive, nontoxic reagent which could be used to regenerate SMZ ex situ or by circulation and extraction within a permeable barrier. Sodium dodecyl sulfate, an anionic surfactant, is relatively expensive and would be mobile if released in groundwater. Furthermore, we found that SMZ regenerated with sodium dodecyl sulfate lost most of its ability to sorb chromate; the sodium dodecyl sulfate binds almost irreversibly to the chromate exchange sites on the SMZ.

In contrast, $\mathrm{SMZ}$ regenerated with $\mathrm{Na}_{2} \mathrm{CO}_{3} / \mathrm{NaOH}$ regained all of its sorption capacity for chromate. Following the $\mathrm{Na}_{2} \mathrm{CO}_{3} / \mathrm{NaOH}$ wash, excess carbonate was neutralized by $0.1 \mathrm{M} \mathrm{HCl}$ $(\mathrm{HCl}$ is another inexpensive, environmentally innocuous reagent which could be used ex situ or circulated in a barrier). Figure 4-17 compares chromate sorption on the regenerated SMZ to sorption on "virgin" SMZ (these experiments used SMZ prepared with HDTMA-Br). Chromate is sorbed at least as effectively by the regenerated $\mathrm{SMZ}$ as by the original material. We thus 
conclude that chromate-saturated SMZ may be fully regenerated at least one time by using inexpensive, environmentally acceptable reagents.

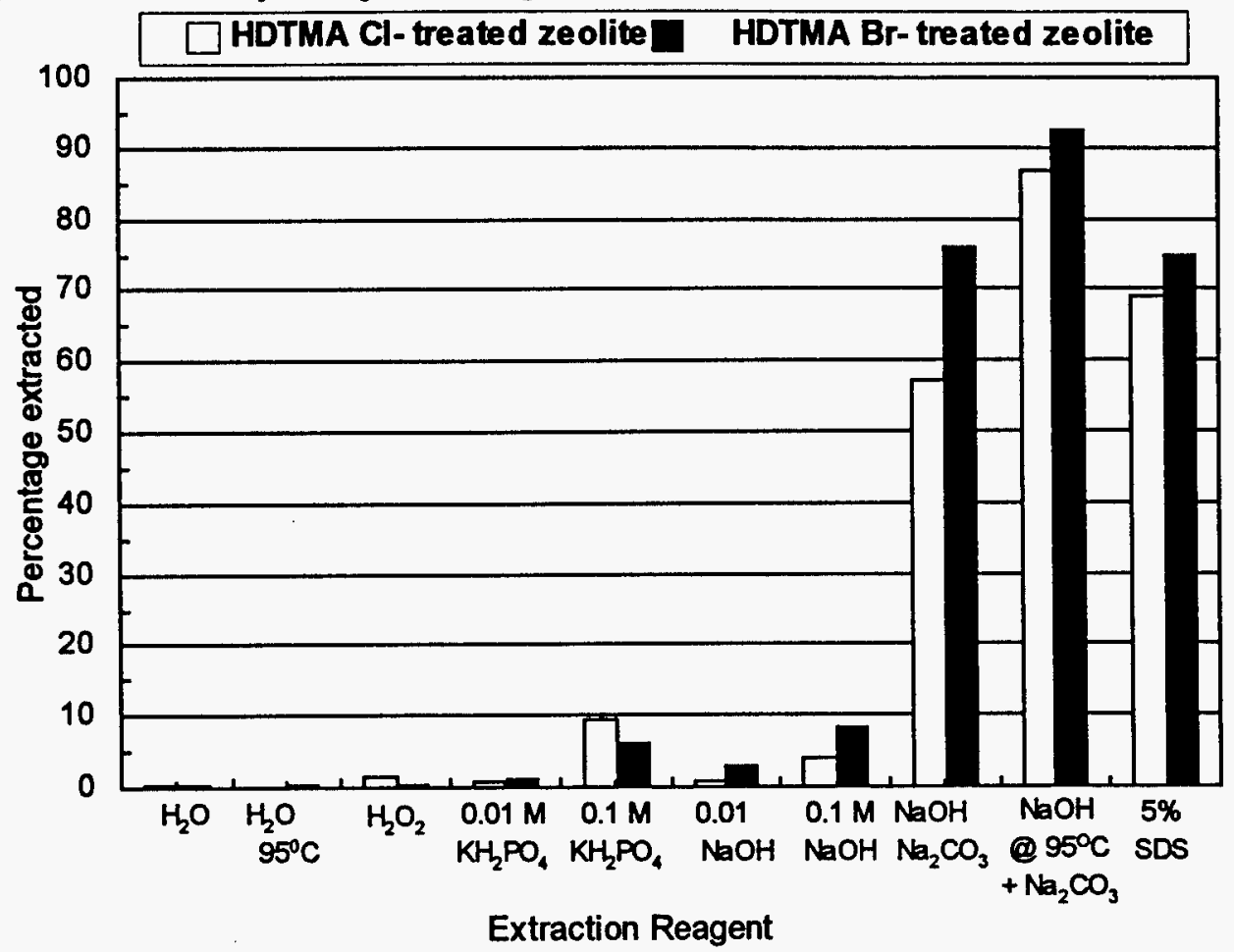

Figure 4- 16 Percentage of sorbed chromate extracted by various reagents from chromate-saturated SMZ.

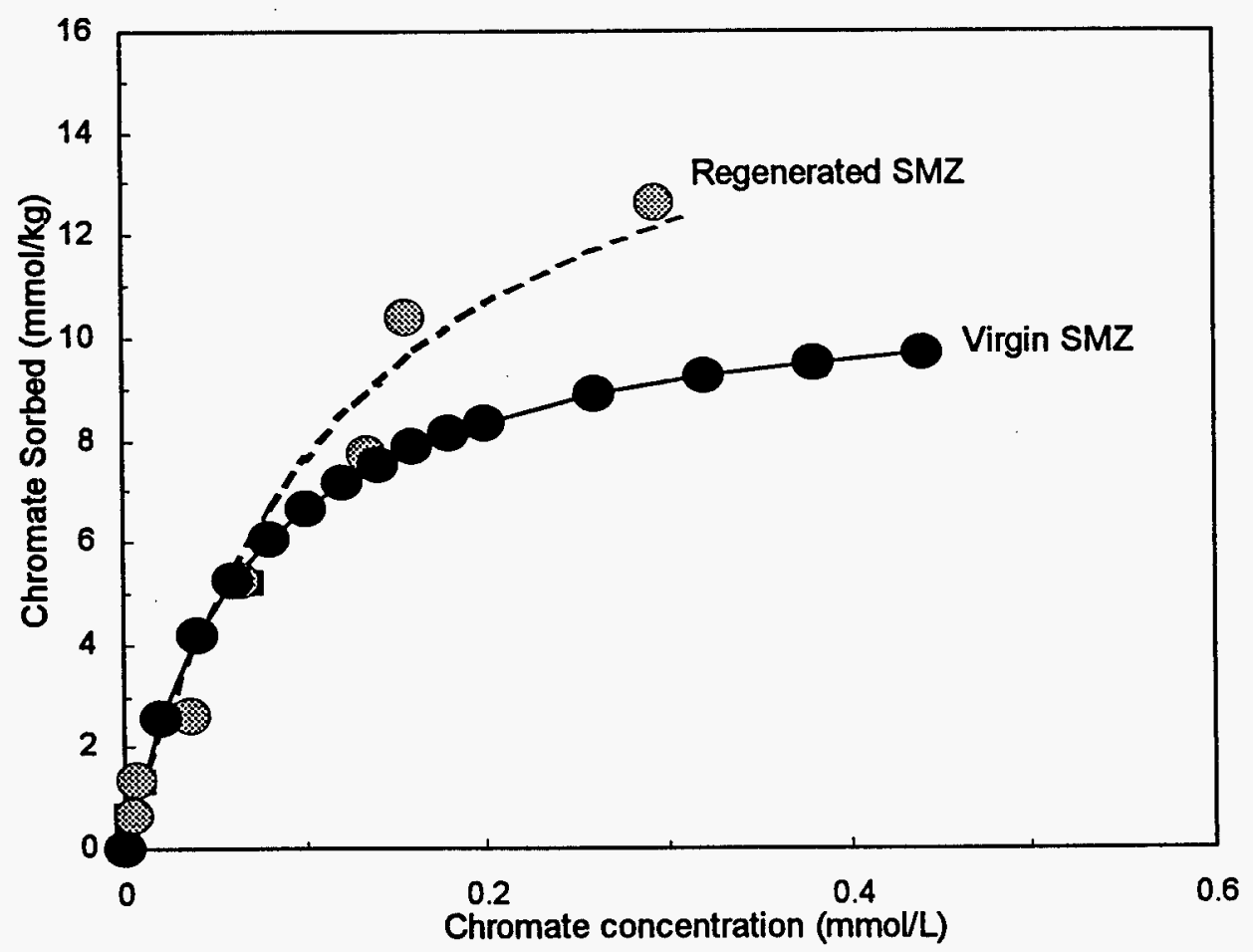

Figure 4- 17 Sorption of chromate on regenerated $\left(\mathrm{Na}_{2} \mathrm{CO} / \mathrm{NaOH}\right)$ and virgin $\mathrm{SMZ}$ 


\section{B. PCE}

Comparison of hexane extracts of PCE-saturated SMZ before and after air stripping showed that air stripping removed $100 \%$ of the PCE. This regenerated SMZ fully regained its sorption capacity for PCE. Figure 4-18 shows that PCE sorption by virgin and air-stripped SMZ is virtually identical. Thus simple, inexpensive air-stripping fully regenerates SMZ for sorption of volatile organics. An air-stripping system could readily be incorporated into a permeable barrier at the time of installation or added to the barrier at a later time.

The SMZ regenerated by $\mathrm{Na}_{2} \mathrm{CO}_{3} / \mathrm{NaOH}$ treatment following chromate saturation also lost none of its ability to retain PCE. Figure 4-19 compares PCE sorption on virgin versus $\mathrm{Na}_{2} \mathrm{CO}_{3} / \mathrm{NaOH}$-regenerated $\mathrm{SMZ}$; the isotherms before and after regeneration are virtually identical.

These results show that SMZ can be regenerated either in situ or ex situ after saturation with both inorganic oxyanions or volatile organics.

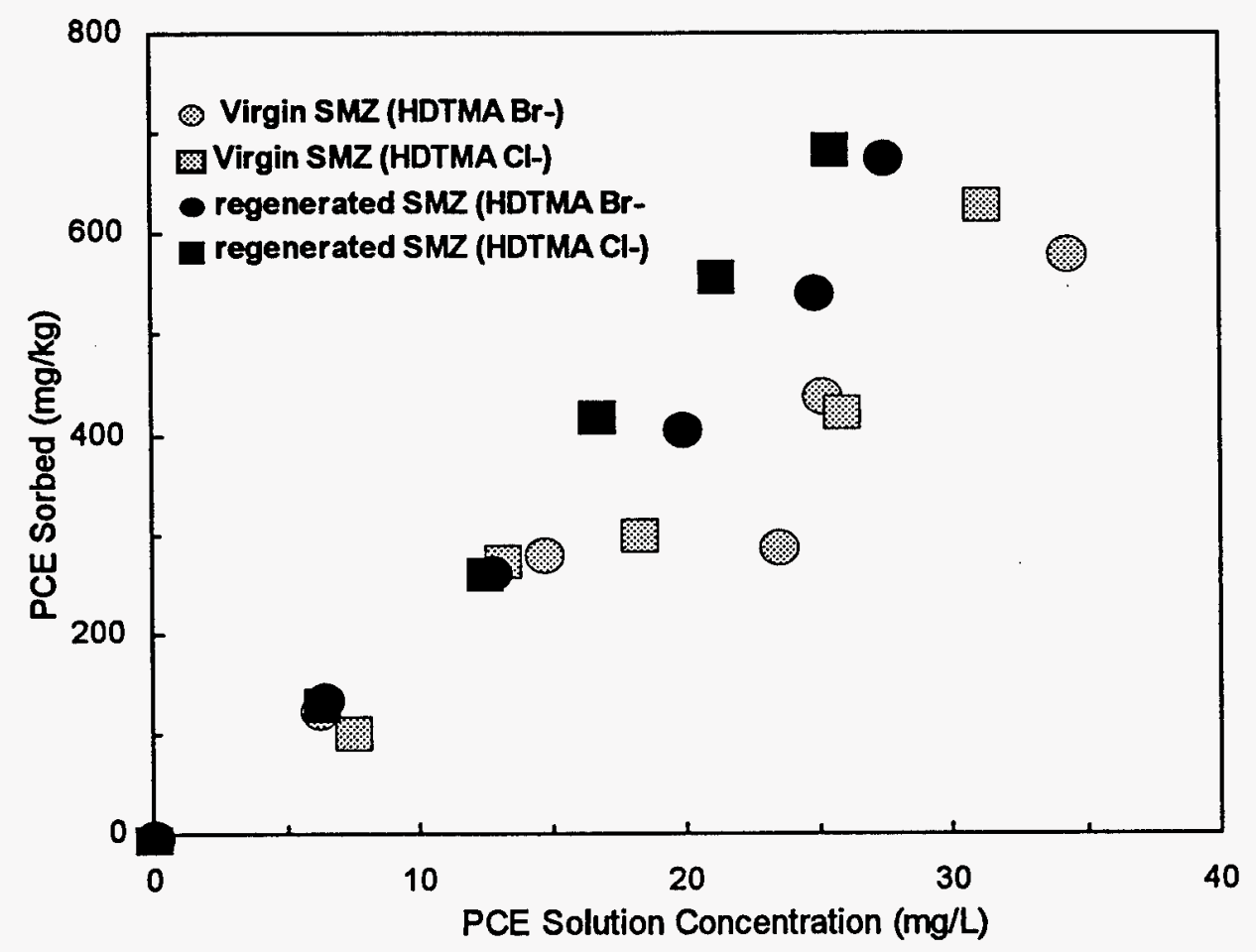

Figure 4- 18 Sorption of PCE on regenerated (air-stripped) and virgin SMZ. 


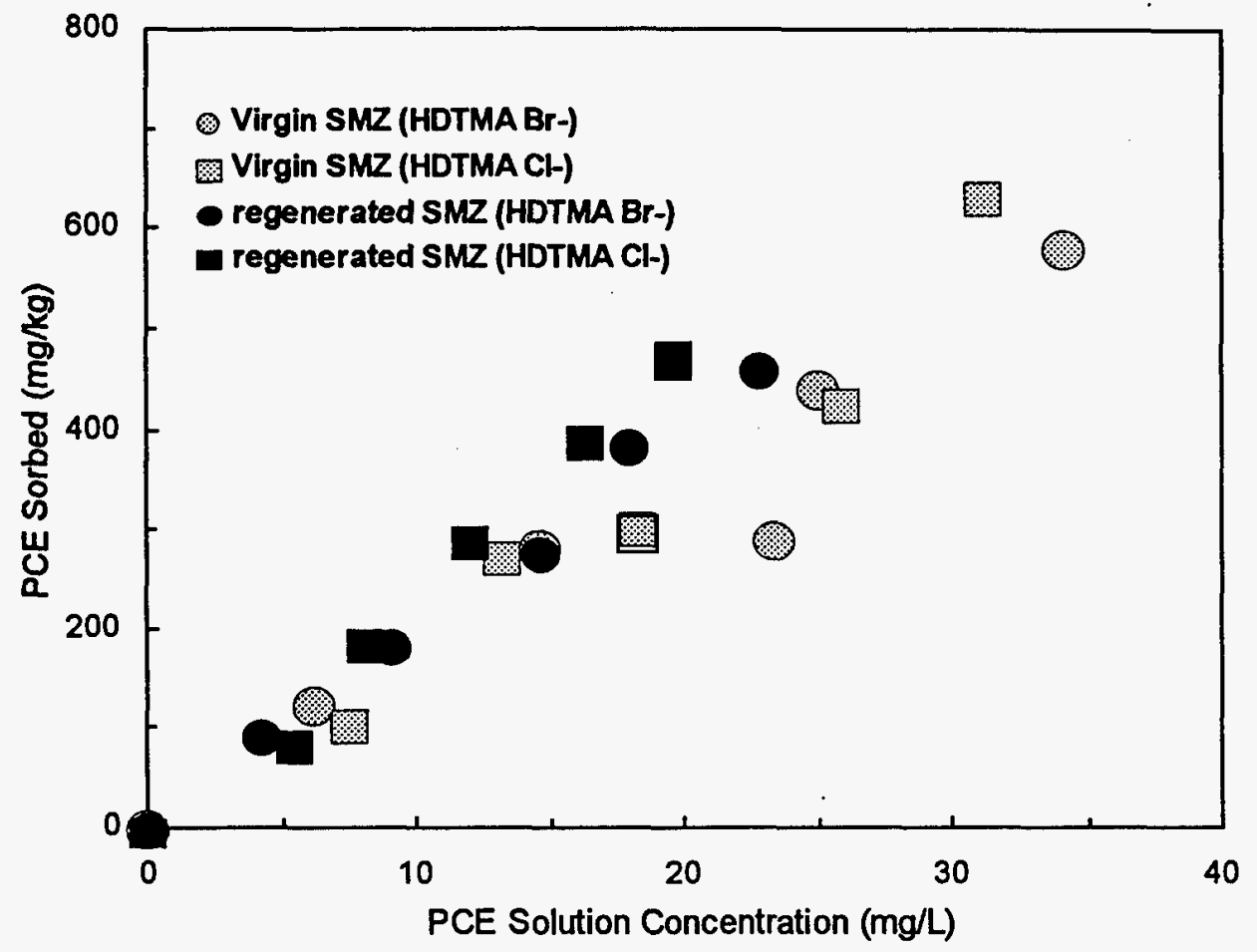

Figure 4- 19 Sorption of PCE on regenerated $(\mathrm{Na2} \mathrm{CO} / \mathrm{NaOH})$ and virgin $\mathrm{SMZ}$

Task 1.6 Determine the ability to predict contaminant movement through beds of SMZ

\section{A. Chromate}

Figure 4-20 shows the ${ }^{3} \mathrm{H}_{2} \mathrm{O}$ breakthrough curves for the one column packed with untreated zeolite and one packed with SMZ. The breakthrough curves for the SMZ columns show evidence of early breakthrough and increased tailing compared to those for untreated zeolite. The difference in transport of the nonreactive ${ }^{3} \mathrm{H}_{2} \mathrm{O}$ is most likely due to the creation of a bimodal pore regime in the SMZ (van Genuchten and Wierenga, 1986), with the surfactant coating partially isolating the internal (zeolitic) water from the more mobile intergranular water.

Figure 4-21 shows chromate breakthrough curves for one column of untreated zeolite and one column of SMZ. Chromate is unretarded by the untreated zeolite, and appears in the effluent of this column in a few hours (less than 1 pore volume). In contrast, chromate is strongly retained by SMZ. Chromate does not appear in the effluent until about $0.5 \mathrm{~d}$ (4 pore volumes), and after 4 $\mathrm{d}$ (32 pore volumes) the chromate concentration in the effluent is only about $40 \%$ of the input concentration. The chromate transport behavior is generally well predicted (solid line in Fig. 4-21) using the batch isotherm data of Fig. 4-5 and the transport parameters from the ${ }^{3} \mathrm{H}_{2} \mathrm{O}$ breakthrough curve of Fig. 4-20. Chromate breaks through somewhat earlier than predicted, however. This is likely the result of incomplete sorption equilibrium under the high flow rate conditions of the column experiment. At groundwater flow velocities, which would typically be at least one order of magnitude lower, such early breakthrough probably will not be observed. 


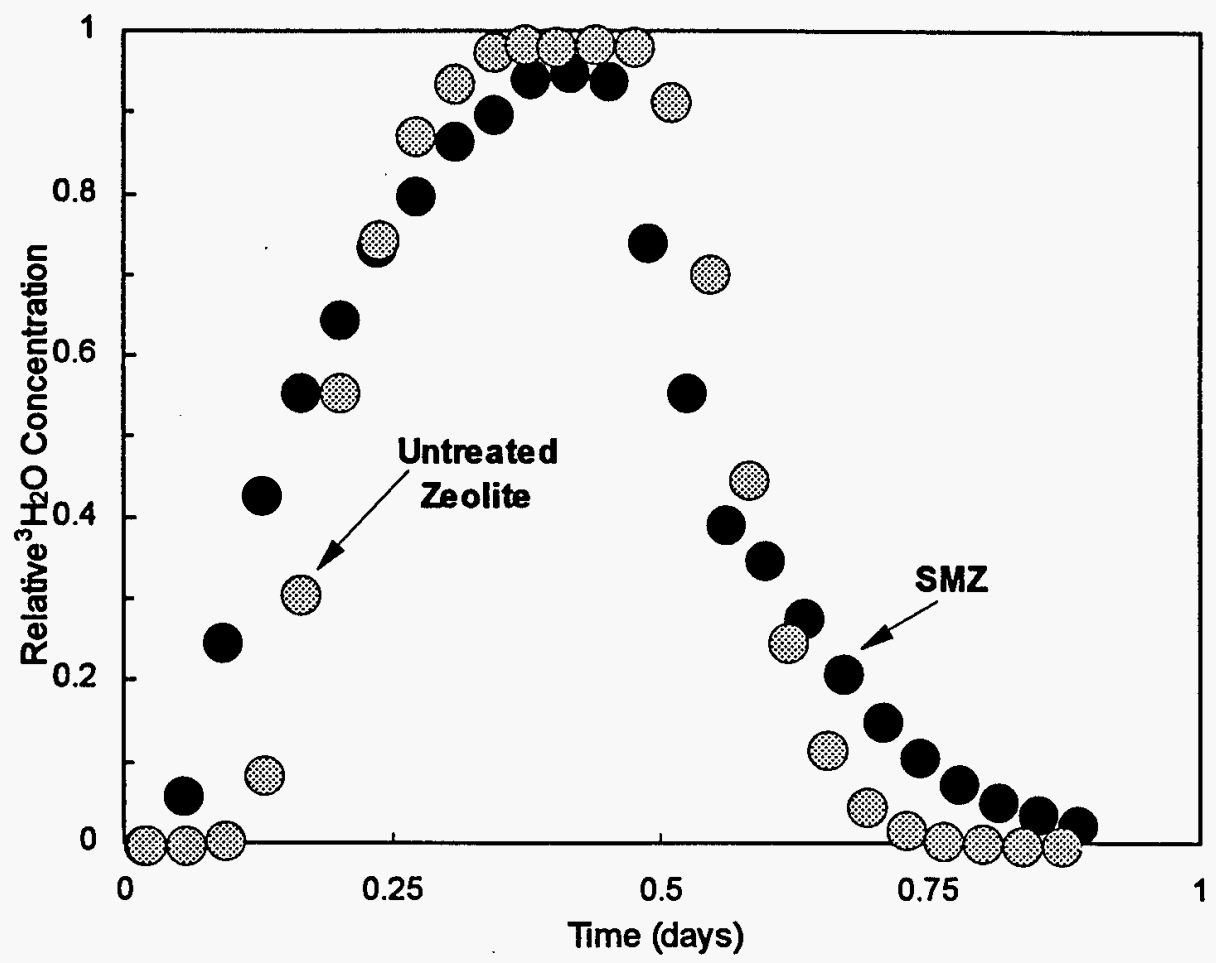

Figure 4- 20 Tritium breakthrough curves for columns packed with untreated zeolite and with SMZ (chromate experiment).

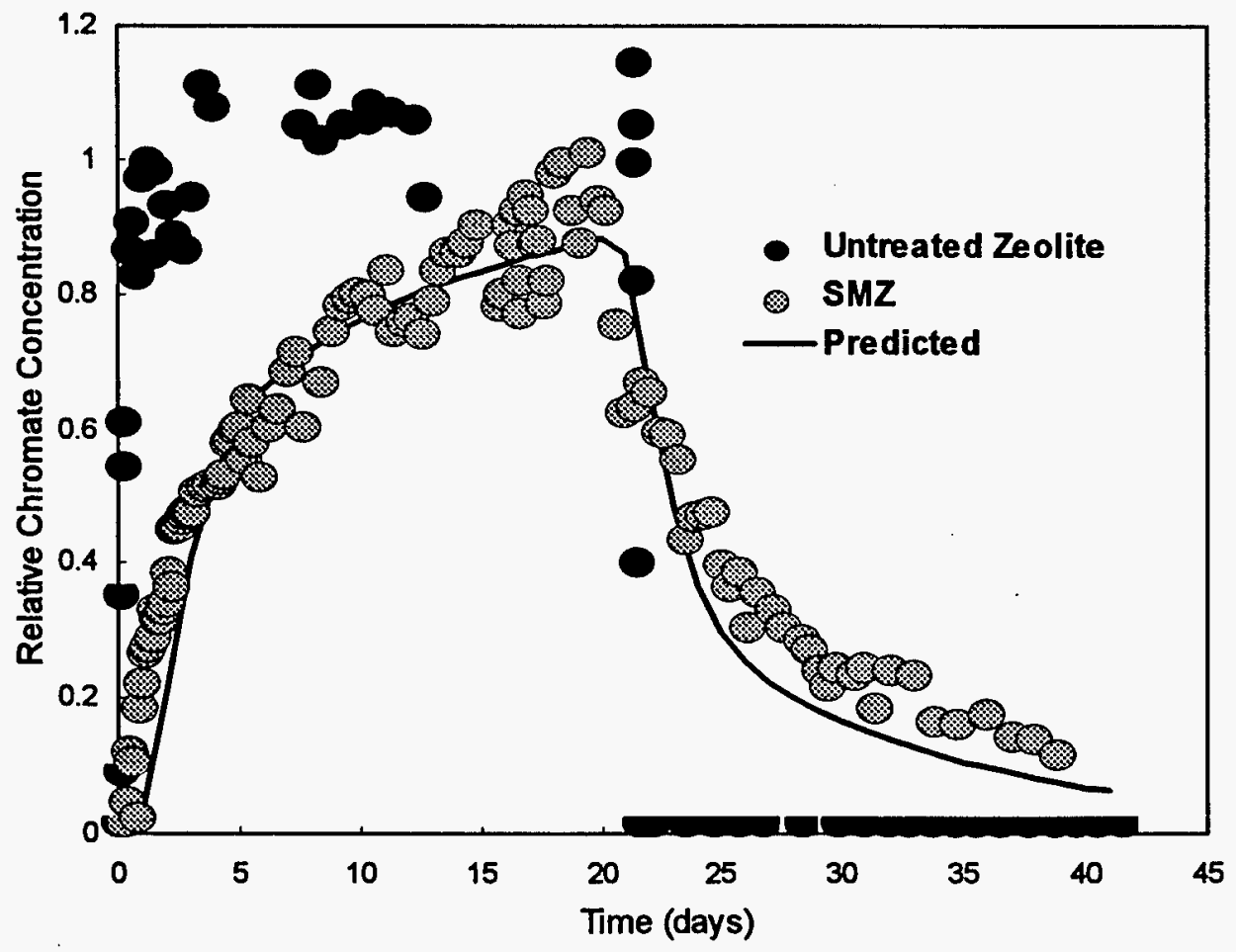

Figure 4- 21 Chromate breakthrough curves for columns packed with untreated zeolite and with SMZ. The predicted line is based on the chromate sorption isotherm data of Fig. 4-5. 


\section{B. PCE}

Figure 4-22 shows the ${ }^{3} \mathrm{H}_{2} \mathrm{O}$ breakthrough curves for one column packed with untreated zeolite and one packed with SMZ. Similar to the chromate transport experiments, curves for the SMZ columns show evidence of early breakthrough and increased tailing compared to those for untreated zeolite.

Figure 4-23 shows PCE breakthrough curves for one column of untreated zeolite and one column of SMZ. The decreasing PCE concentration with time in the effluent from the untreated column reflects a decreasing input concentration due to PCE diffusion through the Teflon fluid reservoir (Fig. 3-2). PCE is unretarded by the untreated zeolite, and appears in the effluent of this column within half a day (less than 1 pore volume). In contrast, almost no PCE has eluted from the SMZ column after almost two days (more than 6 pore volumes). The maximum PCE concentration in the SMZ column never exceeds $50 \%$ of the influent concentration, and after more than 30 pore volumes about $30 \%$ of the PCE is still retained in the SMZ column.

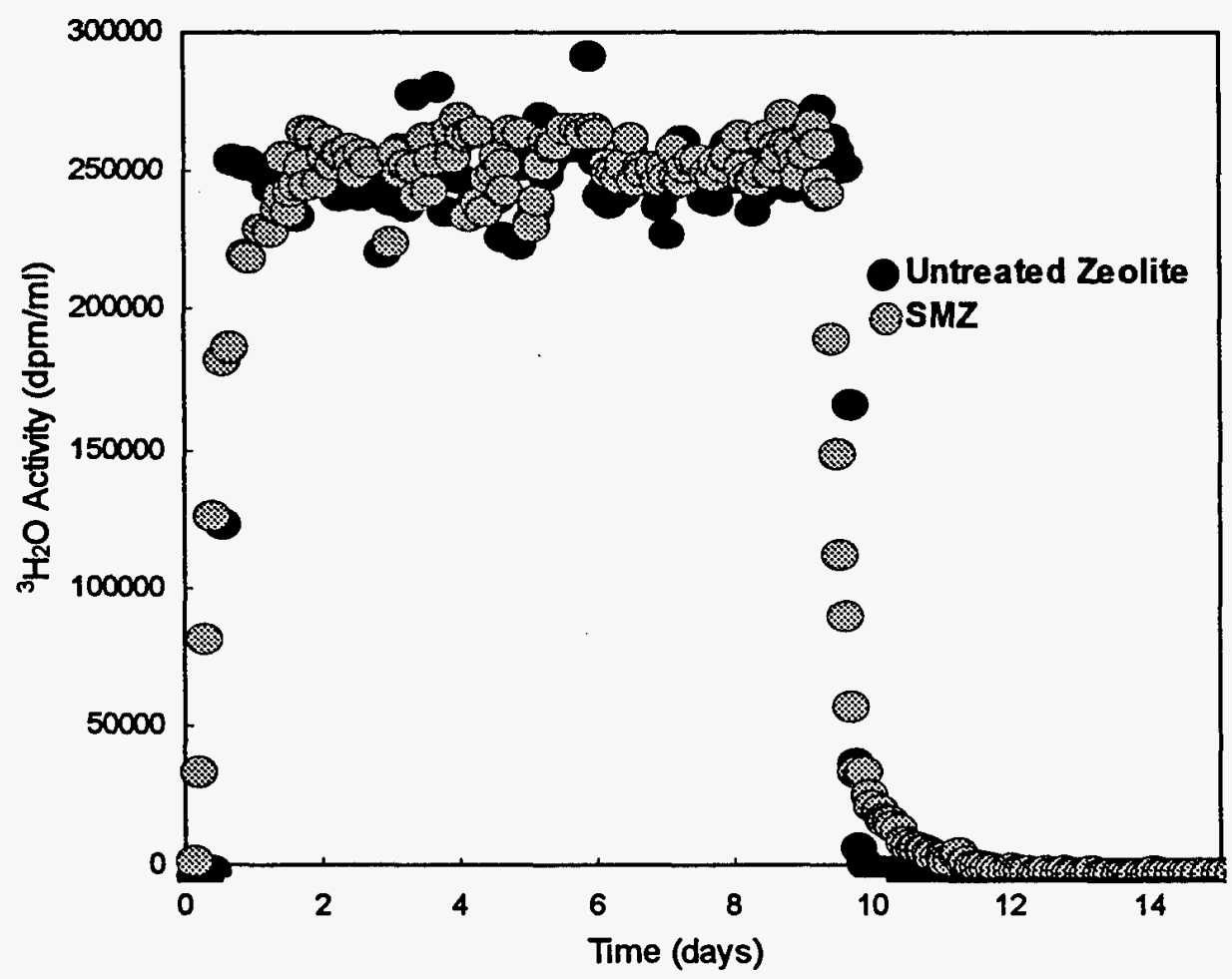

Figure 4- 22 Tritium breakthrough curves (raw count values) for columns packed with untreated zeolite and with SMZ (PCE experiment). 


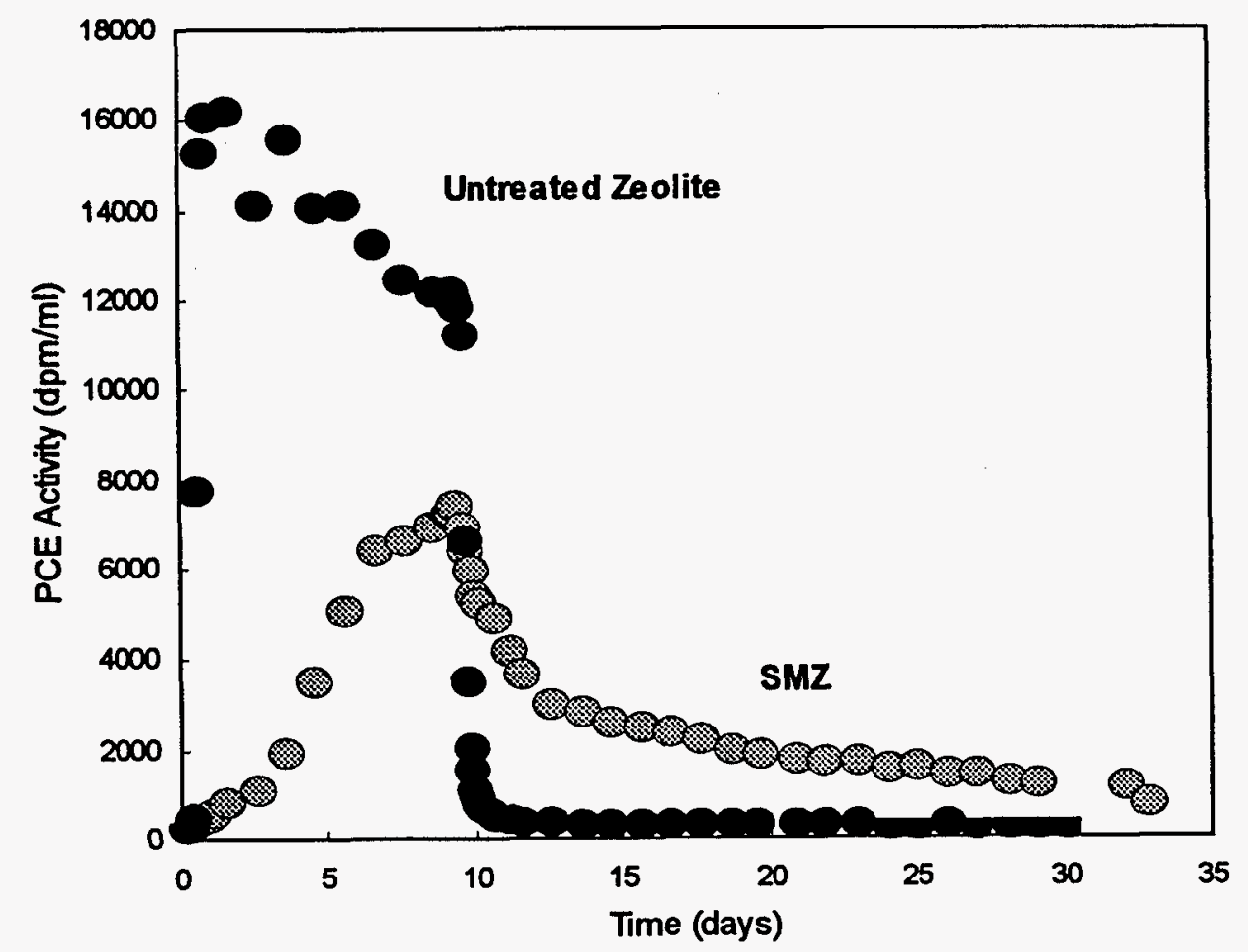

Figure 4- 23 PCE breakthrough curves (raw count values) for columns packed with untreated zeolite and with SMZ.

\section{Task $1.7 \quad$ Topical Report}

The present Topical Report represents the results of Task 1.7. 


\subsection{ECONOMIC ANALYSIS}

Table 5-1 summarizes the properties and costs of HDTMA available from various commercial suppliers. There is a large variation in the cost per unit of HDTMA active ingredient among the various brands. The HDTMA-Cl materials Carsoquat and Ammonyx are the least expensive per unit of HDTMA, with a cost of about $\$ 3.65 \mathrm{lb}^{-1}$ of active ingredient. The SMZ prepared with HDTMA-Cl was also about $50 \%$ more effective in sorbing chromate than was SMZ prepared with HDTMA-Br (Table 5-1, and Figs. 4-7 and 4-8) and as effective in sorbing PCE (Figs. 4-10 and 4-11). In addition, less HDTMA-Cl is required to prepare SMZ with maximum sorption capacities for these contaminants (Table 5-1).

At a maximum HDTMA loading rate of $150 \mathrm{mmol} \mathrm{kg}^{-1}, \mathrm{SMZ}$ is about $4 \%$ HDTMA by weight. Thus, about $80 \mathrm{lb}$ of HDTMA as HDTMA-Cl would be required to produce a ton of SMZ. Assuming a cost of raw, sized zeolite of $\$ 60-\$ 100 \mathrm{ton}^{-1}$, and a cost of $\$ 3.65 \mathrm{lb}^{-1}$ for HDTMA, materials cost for SMZ would be in the range of $\$ 350-\$ 400$ ton $^{-1}$. The costs of combining the HDTMA and the zeolite, plus drying, should add no more than $20 \%$ to the materials cost (P.S. Freeman, St. Cloud Mining Co.). Accordingly, SMZ ready for installation in a permeable barrier can be produced for less than $\$ 500$ ton $^{-1}$.

Since the density of SMZ is about $1 \mathrm{~g} \mathrm{~cm}^{-3}$, the cost per unit volume would be about $\$ 15$ $\mathrm{ft}^{-3}$. The unit weight and volume cost of $\mathrm{SMZ}$ is low compared to activated carbon (several thousand dollars per ton), ion exchange resins (several hundred dollars per cubic foot) and zero valent iron ( $\$ 300-350$ ton $^{-1}$, or about $\$ 30 \mathrm{ft}^{-3}$ because of the high iron filing density of $2.5-2.9 \mathrm{~g}$ $\mathrm{cm}^{-3}$ ). Thus $\mathrm{SMZ}$ appears economically competitive as a permeable barrier material. It also has potential as an alternative sorbent for a variety of other environmental applications, including pump and treat systems and leachate concentration systems, particularly where multiple water contaminants are present.

Table 5- 1 . Commercial sources, properties, and costs of HDTMA.

HDTMA Trade Name

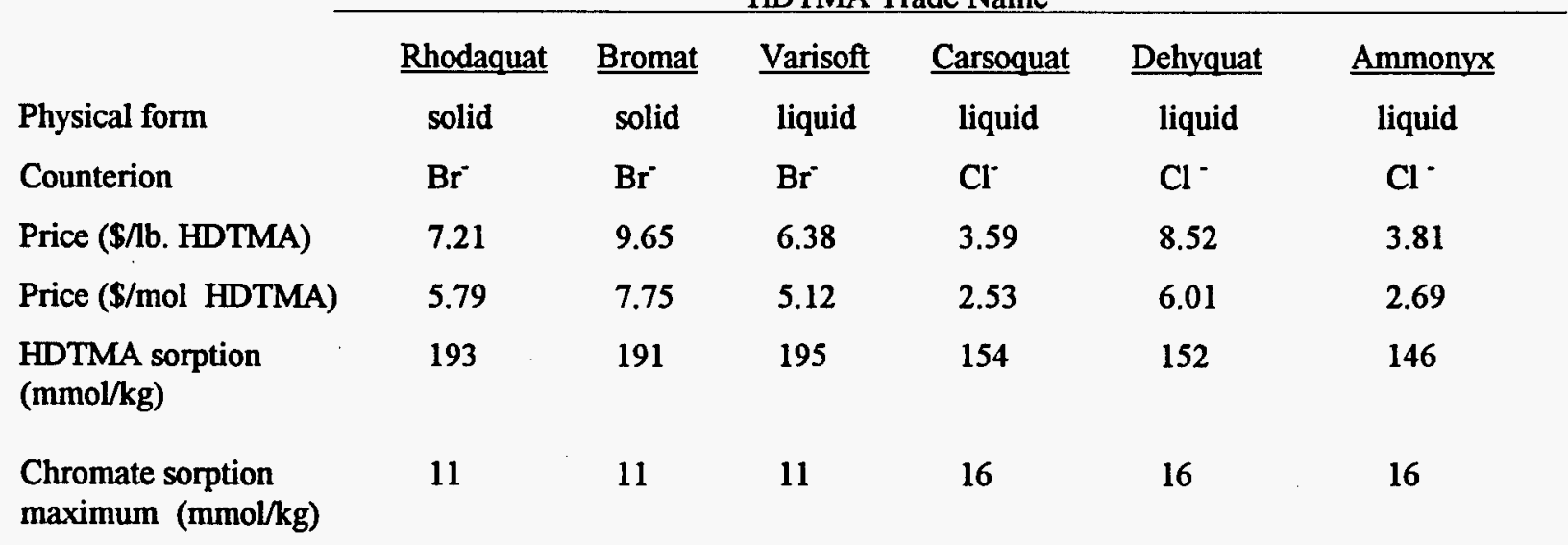




\subsection{CONCLUSIONS}

\section{A. Results of Phase I}

All of the tasks of Phase I have been successfully completed or are in the process of being completed. Specifically, we showed that:

1. Large quantities of SMZ can be produced with simple mixing equipment to prepare a material with good sorbent properties for soluble organics and metal anions.

2. Surfactant-modified zeolite retains its contaminant sorption properties in waters from different sources which vary in ionic strength, $\mathrm{pH}$, and the presence of potentially competing species. The sorption properties for PCE are little affected by the other components of the water. The sorption of chromate can be reduced in the presence of other multivalent anions such as sulfate, but SMZ shows a strong preference for chromate even in this situation.

3. Surfactant-modified zeolite is stable under extreme conditions of water chemistry and biological activity. Little surfactant was removed from the surface under oxidizing, reducing, high or low $\mathrm{pH}$, or high ionic strength conditions. SMZ was virtually unaffected by microbial activity under aerobic or anaerobic conditions.

4. Surfactant-modified zeolite saturated with PCE or chromate can be completely regenerated and attain its original sorption capacity for these contaminants.

5. The transport of chromate and PCE through packed beds of SMZ should be predictable. Since PCE shows linear sorption on SMZ, and chromate shows Langmuir-type sorption, their transport behavior can be predicted using standard models such as CXTFIT (Toride et al.) and MOC (Konikow et al.). The validation of our predictions is currently underway.

\section{B. Outlook for Phase II}

The success of Phase I justifies proceeding with Phase II of the proposed Scope of Work, Pilot-Scale Testing of Barrier Technology. This pilot-scale testing can be performed in a large, highly controlled test bed or as a small-scale installation at an actual contaminated site.

Several potential test-bed facilities have been identified. Test bed facilities at Los Alamos National Laboratory and at the University of Wyoming are suitable for Phase II; investigators at each of these facilities have provided acceptable cost quotations for the required work. A suitable facility is also available at the Oregon Graduate Institute; the operators of this facility will be contacted before completion of Phase I to determine their interest in bidding on a Phase II subcontract.

A small-scale field installation for Phase II would offer the advantage of testing barrier installation and monitoring procedures under actual field conditions. The disadvantage would be uncertainties associated with obtaining the required permits in a time frame consistent with Phase II scheduling and budget. The managers in charge of DOD's proposed national technology test site at Dover Air Force Base, DE, have expressed a willingness to work with the Project Manager 
in installing a pilot-scale SMZ permeable barrier. DOD would provide logistical support (monitoring, field-site characterization) at Dover. We will continue to investigate this option. A decision will be made during the final month of Phase I regarding which alternative (test-bed facility or pilot-scale field installation) will be pursued in Phase II. Primary consideration will be given to the ability of potential subcontractors to meet Phase II scheduling. 


\subsection{REFERENCES}

Breck, D.W. 1974. Zeolite molecular sieves: structure, chemistry, and use. John Wiley and Sons, New York.

Bowman, R.S., G.M. Haggerty, R.G. Huddleston, D. Neel, and M. Flynn. 1995. Sorption of nonpolar organics, inorganic cations, and inorganic anions by surfactant-modified zeolites. p. 54-64. In D.A. Sabatini, R.C. Knox, and J.H. Harwell (eds.). Surfactant-enhanced remediation of subsurface contamination. ACS Symposium Series 594. American Chemical Society, Washington, DC.

Carey, J.W., E.J. Sullivan, and R.S. Bowman. 1996. Calorimetric determination of the heat of sorption of surfactants (HDTMA and TEA) on clinoptilolite.. Clay Minerals Society Annual Meeting, 15-20 June 1996, Gatlinburg, TN.

Fetter, C.W. 1993. Contaminant hydrogeology. Macmillan Publishing Co., New York.

Flynn, M.M., 1994. Sorption of Chromate and Lead onto Surface-Modified Zeolites. New Mexico Institute of Mining and Technology, Masters Thesis.

Groffman, A., S. Peterson, and D. Brookins. 1992. Removing lead from wastewater using zeolite. Water Environ. and Tech. May 1992:54.

Haggerty, G.M., and R.S. Bowman. 1994. Sorption of inorganic anions by organo-zeolites. Environ. Sci. Technol. 28:452-458.

Huddleston, R.E., 1990. Surface-Altered Hydrophobic Zeolites as Sorbents for Hazardous Organic Compounds. New Mexico Institute of Mining and Technology, Masters Thesis.

James, B. R. and R. J. Bartlett. 1983. Behavior of chromium in soils: VII. Adsorption and reduction of hexavalent forms. J. Environ. Qual. 12:177-181.

James, B. R., J. C. Petura, R. J. Vitale, and G. R. Mussoline. 1995. Hexavalent chromium extraction from soil: a comparison of five methods. Environ. Sci. Technol. 29:2377-2381.

Konikow, L.F., G.E. Granato, and G.Z. Hornberger. 1994. User's guide to revised method-ofcharacteristics solute-transport model (MOC--Version 3.1). U.S. Geological Survey WaterResources Investigations Report 94-4115. U.S. Geological Survey, Denver, CO.

Ming, D.W., and F.A. Mumpton. 1989. Zeolites in soil. p. 873-911. In J.B. Dixon and S.B Weed (eds) Minerals in soil environments, 2 nd ed. Soil Science Society of America, Madison, WI.

Ososkov, V., and J. W. Bozzelli. 1994. Removal of Cr(VI) from chromium contaminated sites by washing with hot water. Hazardous Waste \& Hazardous Materials 11:511-517. 
Puls, R. W., D. A. Clark, C. J. Paul, and J. Vardy. 1994. Transport and transformation of hexavalent chromium through soils and into ground water. J. Soil Contamination 3:203-224.

Neel, D., and R.S. Bowman. 1992. Sorption of organics to surface-altered zeolites. p. 57-61. In Proc. 36th Annual New Mexico Water Conf., 7-8 November 1991, Las Cruces, NM.

Newsom, J.M., 1986. The zeolite cage structure. Science 231:1093-1099.

Nye, J. V., W. F. Guerin, and S. A. Boyd. 1994. Heterotrophic activity of microorganisms in soils treated with quaternary ammonium compounds. Environ. Sci. Technol. 28:944-951.

Sheppard, R.A., and A.J. Gude. 1982. Mineralogy, chemistry, gas adsorption, and $\mathrm{NH}_{4}{ }^{+}$ exchange capacity for zeolitic tuffs from the western United States. Open File Report 82-969, U.S. Geological Survey, United States Department of the Interior.

Sullivan, E.J., D.B. Hunter, and R.S. Bowman. 1996. Topological and thermal properties of surfactant-modified clinoptilolite studied by tapping-mode atomic force microscopy and high-resolution thermogravimetric analysis. Clays Clay Min. 44:(in press).

Toride, N., F.J. Leij, and M.Th. van Genuchten. 1995. The CXTFIT code for estimating transport parameters from laboratory or field tracer experiments, Version 2.0. U.S. Salinity Laboratory, USDA-ARS, Riverside, CA.

Van Genuchten, M.Th., and P.J. Wierenga. 1986. Solute dispersion coefficients and retardation factors. P. 1025-1054 In A. Klute (ed) Methods of soil analysis. Part 1. Physical and mineralogical methods, 2nd ed. American Society of Agronomy, Madison, WI. 


\subsection{LIST OF ACRONYMS}

CERCLA Comprehensive Environmental Response, Compensation, and Liability Act of 1983

DOD Department of Defense

DOE Department of Energy

GC Gas chromatography

HPLC High performance liquid chromatography

HDTMA Hexadecyltrimethylammonium, a cationic surfactant

$\mathrm{K}_{\mathrm{D}} \quad$ Linear sorption coefficient

$\mathrm{K}_{\mathrm{ow}} \quad$ Octanol/water partition coefficient

PCE Perchloroethylene

RCRA Resource Conservation and Recovery Act of 1976

SARA Superfund Amendments and Reauthorization Act of 1986

SMZ Surfactant-modified zeolite 


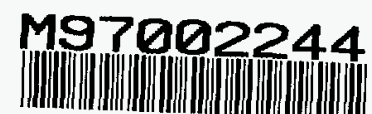

Report Number (14) DOE/mC/32108--5597

Publ. Date (11)

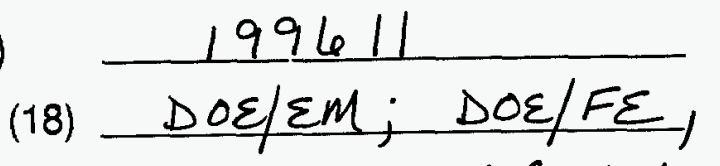

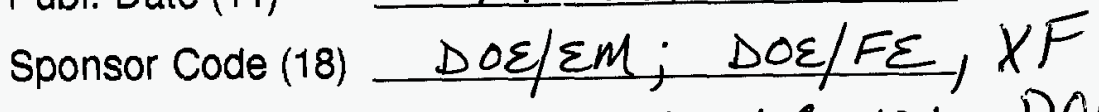

UC Category (19) uC-2000; uC-101, DOE/ER 